\title{
RESEARCH
}

Open Access

\section{TRPV1 mediates astrocyte activation and interleukin- $1 \beta$ release induced by hypoxic ischemia (HI)}

Xing-Liang Yang ${ }^{1+}$, Xin Wang ${ }^{1+}$, Lin Shao ${ }^{1}$, Guang-Tong Jiang ${ }^{1}$, Jia-Wei Min ${ }^{1}$, Xi-Yu Mei ${ }^{2}$, Xiao-Hua He ${ }^{3}$, Wan-Hong Liü, Wen-Xian Huang ${ }^{1,5^{*}}$ and Bi-Wen Peng ${ }^{7^{*}}$ (D)

\begin{abstract}
Background: Hypoxic-ischemic encephalopathy (HIE) is a serious birth complication with high incidence in both advanced and developing countries. Children surviving from HIE often have severe long-term sequela including cerebral palsy, epilepsy, and cognitive disabilities. The severity of HIE in infants is tightly associated with increased IL-1 $\beta$ expression and astrocyte activation which was regulated by transient receptor potential vanilloid 1 (TRPV1), a non-selective cation channel in the TRP family.
\end{abstract}

Methods: Neonatal hypoxic ischemia (HI) and oxygen-glucose deprivation (OGD) were used to simulate HIE in vivo and in vitro. Primarily cultured astrocytes were used for investigating the expression of glial fibrillary acidic protein (GFAP), IL-1 $\beta$, Janus kinase 2 (JAK2), signal transducer and activator of transcription 3 (STAT3), and activation of the nucleotide-binding, oligomerization domain (NOD)-like receptor pyrin domain-containing protein 3 (NLRP3)

inflammasome by using Western blot, q-PCR, and immunofluorescence. Brain atrophy, infarct size, and neurobehavioral disorders were evaluated by Nissl staining, 2,3,5-triphenyltetrazolium chloride monohydrate (TTC) staining and neurobehavioral tests (geotaxis reflex, cliff aversion reaction, and grip test) individually.

Results: Astrocytes were overactivated after neonatal HI and OGD challenge. The number of activated astrocytes, the expression level of IL-1 $\beta$, brain atrophy, and shrinking infarct size were all downregulated in TRPV1 KO mice. TRPV1 deficiency in astrocytes attenuated the expression of GFAP and IL-1 $\beta$ by reducing phosphorylation of JAK2 and STAT3. Meanwhile, IL-1 $\beta$ release was significantly reduced in TRPV1 deficiency astrocytes by inhibiting activation of NLRP3 inflammasome. Additionally, neonatal HI-induced neurobehavioral disorders were significantly improved in the TRPV1 $\mathrm{KO}$ mice.

Conclusions: TRPV1 promotes activation of astrocytes and release of astrocyte-derived IL-1 $\beta$ mainly via JAK2-STAT3 signaling and activation of the NLRP3 inflammasome. Our findings provide mechanistic insights into TRPV1mediated brain damage and neurobehavioral disorders caused by neonatal $\mathrm{HI}$ and potentially identify astrocytic TRPV1 as a novel therapeutic target for treating HIE in the subacute stages (24 h).

Keywords: HI, Astrocyte, TRPV1, IL-1ß

\footnotetext{
*Correspondence: langer-118@163.com; pengbiwen@whu.edu.cn

${ }^{+*}$ Y.X.L. and W.X. contributed equally to this study as co-first authors.

${ }^{1}$ Department of Physiology, Hubei Provincial Key Laboratory of

Developmentally Originated Disorder, School of Basic Medical Sciences,

Wuhan University, Donghu Rd185\#, Wuhan 430071, Hubei, China

${ }^{5}$ Department of Pathology, Renmin Hospital of Wuhan University, Jiefang

Rd238\#, Wuhan 430071, Hubei, China

Full list of author information is available at the end of the article
}

(c) The Author(s). 2019 Open Access This article is distributed under the terms of the Creative Commons Attribution 4.0 International License (http://creativecommons.org/licenses/by/4.0/), which permits unrestricted use, distribution, and reproduction in any medium, provided you give appropriate credit to the original author(s) and the source, provide a link to the Creative Commons license, and indicate if changes were made. The Creative Commons Public Domain Dedication waiver (http://creativecommons.org/publicdomain/zero/1.0/) applies to the data made available in this article, unless otherwise stated. 


\section{Introduction}

HIE resulting from oxygen deprivation and blood flow reduction to the brain is a common cause of brain damage [1]. The mechanisms involved in the brain damage include excitotoxicity, apoptosis, and glial overactivation [2]. Although the importance of microglial activation in hypoxia-induced neuroinflammation is well explored [3], the role of astrocyte activation in this process has attracted more attention. It has been explored that activation of astrocytes under pathological conditions [4], such as ischemic damage [5] and neuroinflammation [6-8], are closely related to the pathogenesis of brain injury [9]. Activation of astrocytes and subsequent increase of IL-1 $\beta$ release are shown to be a key determinant of the outcome and prognosis of HIE [10-12]. Astrocytes are the predominant source of IL-1 $\beta$ in post-traumatic stress disorder [13] and prion disease [14]. Active NLRP3 inflammasome, which cleaves the pro-inflammatory cytokines IL-1 $\beta$ to its active form [15], has been detected in astrocytes in several animal models of intracerebral hemorrhage, such as ischemia/reperfusion injury and hemorrhage transgenic amyotrophic lateral sclerosis [16-19]. Moreover, inhibiting the activation of NLRP3 inflammasome attenuates neonatal HI-induced brain injury in rats [20, 21], and systemic neutralizing IL- $1 \beta$ by infusions of anti-interleukin- $1 \beta$ antibodies reduces short-term brain injury after cerebral ischemia in the ovine fetus [22].

TRPV1 channel is the prototypic member of the TRP family and displays dynamic ion selectivity for ions including $\mathrm{H}^{+}, \mathrm{Na}^{+}, \mathrm{Ca}^{2+}$, and $\mathrm{Mg}^{2+}$ [23]. In the CNS, TRPV1 participates in synaptic transmission, neurogenesis, and neuroinflammation [24, 25]. Recent studies suggest that TRPV1 is functionally expressed in CNS glial cells, especially microglia and astrocytes [26, 27]. In astrocytes, TRPV1 activation mediates its migration, chemotaxis, and the expression of GFAP, during stress and injury [28]. TRPV1 activation stimulates a JAK2-STAT3 pathway to regulate astrocyte activation, astrocyte hypertrophy, and the expression of cytokines such as IL-1 $\beta$ and IL-6 in vitro and in vivo [29-32]. TRPV1 activation participated in neonatal brain injuries $[33,34]$, and overactivated astrocytes exacerbate neurological deficits [35]. These findings strongly suggest that TRPV1 may mediate astrocytic activation and IL-1 $\beta$ release in HIE.

We have previously reported that TRPV1 promoted the activation of microglia and upregulated the expression of TNF, IL-1 $\beta$, IL-6, and high mobility group box 1 (HMGB1) in repetitive febrile seizure (FS) mice [36]. The main purpose of the present study was to determine whether TRPV1 aggravated brain damages, neurological deficits by promoting astrocytes activation, and neuroinflammation in a mouse model of neonatal HI. We found that in the subacute stage $(24 \mathrm{~h})$, TRPV1 activation increases the phosphorylation of JAK2 and STAT3, which results in an increased expression of GFAP and IL-1 3 . TRPV1 activation promotes the activation of the NLRP3 inflammasome, which drives the release of IL-1 $\beta$. Furthermore, knocking out TRPV1 significantly improves neonatal HI-induced neurobehavioral disorders.

\section{Materials and methods}

\section{Animal models and treatments}

B6.129X1-TRPV1 KO mice used in experiments were from the Jackson Laboratory, and wild-type (WT) mice were provided by the Hubei Province Center for Animal Experiments. Animal experiments were approved by the Care and Use Committee of Wuhan University Medical School. B6.129X1-TRPV1 KO mice and wild-type mice were both on a C57BL/6J background. Mice were grouped randomly and kept on a 12-h light-dark cycle, in a room maintained at $25 \pm 2{ }^{\circ} \mathrm{C}$ and relative humidity of $60 \sim 80 \%$. All mice were housed at the animal facility of the Animal Biosafety Level III Laboratory (ABSL-III) of the Wuhan University. The day of the birth was defined as postnatal day zero (P0). Mice pups $(n=160)$ of P9 were used in this study and randomly divided into the five groups $(n=32$ each group): WT-Sham, WT-HI, WT-Capsaicin-HI (intraperitoneal injection of $3 \mathrm{mg} / \mathrm{kg}$ capsaicin $0.5 \mathrm{~h}$ before neonatal HI), KO-Sham, and KO-HI.

\section{Neonatal hypoxia-ischemia model}

A well-characterized model of neonatal HI was followed as a previously described [2, 37]. P9 C57BL/6 WT and TRPV1 KO mice of both genders $(5 \pm 1 \mathrm{~g}$ of body weight, equal males, and females were chosen for each group) were anesthetized by inhalation of isoflurane. The sterilized skin was incised with an ophthalmology scissor. And the right pulsating carotid artery was carefully separated. The upper and lower ends of the right carotid artery were tied using 4-0 surgical suture before cutting the artery in the middle. The skin incision was sutured with the same surgical suture. All the above experimental surgical instruments were sterilized. After $2 \mathrm{~h}$ of recovery, the pups were placed in an airtight transparent chamber, and the chamber was placed into a $37^{\circ} \mathrm{C}$ incubator to maintain a constant thermal environment. The pups were maintained in $8 \% \mathrm{O}_{2}$ in $\mathrm{N}_{2}$ for $45 \mathrm{~min}$. After the hypoxic process, the mouse pups were put back in the cages. Successful HI model showed significant edema in the ipsilateral hemisphere, while the sham group (underwent anesthesia, neck incision, and suture) did not. The mortality of this model was about $10 \%$.

\section{Nissl staining}

We followed detailed protocols that have been previously reported [38]. Briefly, at $24 \mathrm{~h}$ after neonatal HI, mice pups were perfused with phosphate-buffered saline 
(PBS) followed by $4 \%$ paraformaldehyde (PFA). The brains were then obtained for Nissl staining following the standard protocol.

\section{Infarct volume measurement}

The procedure has been previously described [39]. At $24 \mathrm{~h}$ post-HI, animals were transcardially perfused with PBS under deep anesthesia. The brains were obtained and sectioned into $2 \mathrm{~mm}$ slices and then immersed in $2 \%$ 2, 3, 5-triphenyltetrazolium chloride monohydrate (TTC) solution at $37^{\circ} \mathrm{C}$ for $10 \mathrm{~min}$, followed by $4 \%$ PFA to completely fix the tissue. The infarct volume was traced and analyzed by ImageJ software (version 1.41).

\section{Primary mouse cortical astrocytes cultures}

Astrocyte culture was prepared as previously described [40]. P0 mice were euthanized after being disinfected with $75 \%$ ethanol. The brain tissue was isolated and then put into the pre-cooled PBS. In order to obtain dissociated cells, meninges were removed and the clean cerebral cortex was digested in Hank's balanced salt solution (HBSS) containing $0.125 \%$ trypsin at $37^{\circ} \mathrm{C}$ for $10 \mathrm{~min}$. Complete growth media $(1 \times$ Dulbecco's modified Eagle's medium (DMEM)/F12, 10\% heat-inactivated fetal bovine serum, 1\% L-glutamine, and $1 \%$ penicillin/streptomycin) were added to terminate the digestion. Gently blow digested tissues with pap dropper and then centrifuge at $1000 \mathrm{rpm}$ for $5 \mathrm{~min}$. Dissociated cells were planted in T75 flasks in glial medium and then maintain at conventional cell culture incubator $\left(37^{\circ} \mathrm{C}, 5 \% \mathrm{CO}_{2}\right)$ for $10-12$ days. To purify astrocytes from microglia and oligodendrocytes, the cells in the T75 were subjected to continuous shaking at $37^{\circ} \mathrm{C}(200 \mathrm{rpm}, 10 \mathrm{~h})$. The remaining cells were identified by immunofluorescence staining with anti-GFAP antibody, and approximately $95 \%$ of the remaining cells were GFAP-positive (data not shown).

\section{OGD progression}

Oxygen-glucose deprivation (OGD) was conducted as described previously [41]. Briefly, astrocytes were grown in complete growth media for 9 days as monolayers in cell culture incubator $\left(95 \% \mathrm{O}_{2}\right.$ and $5 \% \mathrm{CO}_{2}$ at $\left.37^{\circ} \mathrm{C}\right)$. And all groups of cell medium were changed to serum-free growth medium $24 \mathrm{~h}$ before OGD. To initiate OGD in vitro, the plates were washed with PBS three times, added OGD medium (serum- and glucose-free DMEM), and placed in a hypoxic/anoxic chamber (1\% $\mathrm{O}_{2}, 5 \% \mathrm{CO}_{2}$, and $94 \% \mathrm{~N} 2$ at $37^{\circ} \mathrm{C}$ ); $3.5 \mathrm{~h}$ later, plates were removed from the anaerobic chamber and OGD medium was changed to complete growth medium. At the same time, control glucose-containing cultures remained in a regular incubator $\left(5 \% \mathrm{CO}_{2}\right.$ and $\left.95 \% \mathrm{O}_{2}\right)$ and the medium was changed to fresh complete growth medium with OGD group. The supernatants and cell extracts were collected after OGD for the following experiments.

\section{Real-time PCR}

Total RNA was extracted from the cortical-derived astrocytes of WT and TRPV1 KO mice from different groups using TRIzol reagent (Invitrogen Life Technologies Corporation, USA) to detect the mRNA level of IL-1 $\beta$, IL-6, TNF, IL-10, NLRP3, an apoptosis-associated speck-like protein containing carboxyl-terminal CARD (ASC), and caspase- 1 .

The quantity of total RNA was measured by a UV spectrophotometer (Biochrom Ltd., UK). Next, reverse transcription was performed using a cDNA synthesis kit (TaKaRa Biotechnology). QPCR was performed on a SYBR-Green premix (TransGen Biotech) according to the manufacturer's specification with the primers listed in Table 1 (Sangon Biotech, Shanghai, Co., Ltd.). The cycling parameters for the CFX96 sequence detection system were $95^{\circ} \mathrm{C}$ for $5 \mathrm{~min}$; 40 cycles of $95^{\circ} \mathrm{C}$ for $15 \mathrm{~s}$, $58^{\circ} \mathrm{C}$ for $30 \mathrm{~s}$, and $72{ }^{\circ} \mathrm{C}$ for $20 \mathrm{~s}$. The expression of target genes was normalized to the mRNA level of $\beta$-actin as an internal control. The $\Delta \Delta \mathrm{Ct}$ values of each group were analyzed, and the mRNA expression of different groups was normalized to $2^{-\Delta \Delta C t}$.

\section{Western blot analysis}

Western blotting was performed according to the manufacturer's specification. The brain tissue samples and astrocytes were collected after neonatal HI and OGD. Proteins were extracted by homogenizing in RIPA buffer (Santa Cruz Biotechnology, Santa Cruz, CA, USA) with phenylmethanesulfonyl fluoride (PMSF) and further centrifuged at $12,000 \mathrm{rpm}$ at $4{ }^{\circ} \mathrm{C}$ for $10 \mathrm{~min}$. The protein concentrations were measured using a detergent-compatible assay (Bio-Rad, Dc protein assay). Equal amounts of protein were loaded on an SDS-PAGE gel. After electrophoresis and transfer to a polyvinylidene fluoride (PVDF) membrane, the membranes were blocked by $5 \%$ skimmed milk for $3 \mathrm{~h}$. The membranes were incubated with the GFAP, JAK2, and STAT3 antibody overnight at $4{ }^{\circ} \mathrm{C}$. Details for the primary and secondary antibodies are listed in Table 2. After incubation, the membranes were washed at least three times with TBST (TBS containing $0.2 \%$ Tween-20) and were then incubated for $1.5 \mathrm{~h}$ with secondary antibodies at room temperature. The membranes were washed again with TBST three times. Finally, the reaction was developed using a chemiluminescent reagent (ECL; Ecl Advantage Inc., Menlo Park, California, USA) and the bands of different proteins were detected using an imaging densitometer (Bio-Rad, Foster City, CA, USA). The data were analyzed using ImageJ software (version 1.41). 
Table 1 q-PCR primer sequences applied

\begin{tabular}{lll}
\hline Primer & Forward primer 5'-3' & Reverse primer 5'-3 \\
\hline NLRP3 & ACGAGTCCTGGTGACTTTGTAT & TAGGTCCACACAGAAAGTTCTCTTA \\
Caspase1 & ATGCCGTGGAGAGAAACAAGG & CCCCTGACAGGATGTCTCCA \\
ASC & ACGAGTCCTGGTGACTTGTAT & TAGGTCCACACAGAAAGTTCTCTTA \\
IL-1 $\beta$ & TAAAGACCTCTATGCCAACACAGT & CTGACTTGGCAGAGGACAAAG \\
IL-6 & TAGTCCTTCCTACCCCAATTCC & TTGGTCCTTAGCCACTACTTC \\
TNF & CCAACAAGGAGGAGAAGTTCC & CTCTGCTTGGTGGTTGCTAC \\
IL-10 & TACTGCTAACCGACTCCTTAATGC & AGAAATCGATGACAGCGCCTC \\
$\beta$-actin & CACGATGGAGGGGCCGGACTCATC & TAAAGACCTCTATGCCAACACAGT \\
\hline
\end{tabular}

\section{Measurement of cytokine by enzyme-linked immunosorbent assay (ELISA)}

The amounts of IL-1 $\beta$ in the culture supernatants in each group of astrocytes were measured by ELISA kit (purchased from 4A Biotech Co., Ltd) according to the manufacturer's instructions. The serum samples of animals or cells from different groups were added into a 96-well plate. Then, it was incubated with the corresponding primary antibody followed for $90 \mathrm{~min}$ at $37^{\circ} \mathrm{C}$. After washing three times with wash buffer, the secondary antibody was added into the plate and incubated for $60 \mathrm{~min}$ at $37^{\circ} \mathrm{C}$. And then the absorbance at $450 \mathrm{~nm}$ (Thermo, USA) was recorded. The concentration of the target protein was calculated according to the standard curve and normalized to the total protein of the samples. Assays were performed independently three times using triplicate wells.

\section{Cell viability assay}

Cell counting kit-8 (CCK-8) assay was performed as previously described [42]. Astrocytes were seeded at a density of $3 \times 10^{4} \mathrm{~mL}^{-1}$ in 96 -well plates. Cell viability was subsequently assessed using the CCK-8 (Dojindo, Tokyo, Japan) according to the manufacturer's instructions. The optical absorbance at $450 \mathrm{~nm}$ was detected using a plate reader (Thermo Fisher Scientific).

\section{Immunofluorescence}

Immunofluorescence staining was used to detect GFAP and IL-1 $\beta$ expression in peri-ischemic brain tissue, assembly of ASC speck and NLRP3 and caspase-1 expression in astrocytes.

Mice in each group were deeply anesthetized with $10 \%$ chloral hydrate and transcardially perfused first with PBS and then fixed in 4\% paraformaldehyde solution at room temperature, dehydrated $24 \mathrm{~h}$ after $\mathrm{HI}$. Serial coronal sections $(5-\mu \mathrm{m}$ thick with injury epicenter located centrally) prepared with cryotome (Leica, Wetzlar, Germany) were used for immunofluorescence labeling. Sections were incubated with 5\% BSA for $30 \mathrm{~min}$ at $37^{\circ} \mathrm{C}$. The tissue slices were then incubated overnight with the anti-GFAP and anti-IL-1 $\beta$ antibodies. For the assessment of assembly of ASC speck and NLRP3 and caspase-1 expression in astrocytes, cells were fixed with methanol, washed with PBS three times, and incubated at $4{ }^{\circ} \mathrm{C}$ with anti-ASC, anti-NLRP3, and anti-caspase- 1 antibodies. On the following day, the sections and cells were washed and subsequently incubated with secondary antibodies Cy3-conjugated Goat Anti-Rabbit IgG $(\mathrm{H}+\mathrm{L})$ and Alexa Fluor 488 Conjugates Goat Anti-Mouse for $1 \mathrm{~h}$ at $37^{\circ} \mathrm{C}$. Dilutions for antibodies were listed in Table 3. Images obtained using a confocal microscope (Leica-LCS-SP8-STED). And images area and intensity were measured in ImageJ.

Table 2 Antibodies for Western blot

\begin{tabular}{|c|c|c|c|c|c|}
\hline Antibody & Host & Company & Cat. no. & Dilution & Duration \\
\hline$\overline{\text { GFAP }}$ & Mouse & Cell signaling & $\# 3670$ & $1: 1000$ & Overnight $4^{\circ} \mathrm{C}$ \\
\hline JAK2 & Rabbit & Cell signaling & \#3230 & $1: 1000$ & Overnight $4^{\circ} \mathrm{C}$ \\
\hline p-JAK2 & Rabbit & Abcam & ab32101 & $1: 2000$ & Overnight $4^{\circ} \mathrm{C}$ \\
\hline STAT3 & Rabbit & Hangzhou HuaAn Biotech & ET1607-38 & $1: 1000$ & Overnight $4^{\circ} \mathrm{C}$ \\
\hline p-STAT3 & Rabbit & Hangzhou HuaAn Biotech & ET1603-40 & $1: 1000$ & Overnight $4^{\circ} \mathrm{C}$ \\
\hline$\beta$-actin & Mouse & Protein tech & HRP-60008 & $1: 10000$ & Overnight $4^{\circ} \mathrm{C}$ \\
\hline Anti-mouse lgG-HRP & Goat & PMK Biotech & PMK-014-091 & 1:100000 & $2 \mathrm{~h} \mathrm{RT}$ \\
\hline Anti-rabbit lgG-HRP & Goat & PMK Biotech & PMK-014-090 & 1:100000 & $2 \mathrm{~h} \mathrm{RT}$ \\
\hline
\end{tabular}


Table 3 Antibodies for immunohistochemistry and fluorescence staining

\begin{tabular}{|c|c|c|c|c|c|c|}
\hline Antibody & Host & Company & Cat. no. & Dilution & Applied & Duration \\
\hline GFAP & Mouse & Cell signaling & $\# 3670$ & $1: 300$ & ICC & Overnight $4^{\circ} \mathrm{C}$ \\
\hline |ba1 & Goat & NOVUS & NB100-1028 & $1: 200$ & ICC & Overnight $4^{\circ} \mathrm{C}$ \\
\hline NRLP3 & Rabbit & NOVUS & NBP2-12446 & $1: 50$ & ICC & Overnight $4^{\circ} \mathrm{C}$ \\
\hline ASC & Mouse & Santa Cruz Bio. & SC-271054 & $1: 50$ & ICC & Overnight $4^{\circ} \mathrm{C}$ \\
\hline Caspase-1 & Mouse & Santa Cruz Bio. & SC-398715 & $1: 50$ & ICC & Overnight $4^{\circ} \mathrm{C}$ \\
\hline$\|-1 \beta$ & Rabbit & Bio-Swamp & PAB30679 & $1: 50$ & ICC & Overnight $4^{\circ} \mathrm{C}$ \\
\hline Anti-rabbit lgG-Cy3 & Goat & Protein tech & SA00009-2 & $1: 50$ & ICC & $1 \mathrm{~h} 37^{\circ} \mathrm{C}$ \\
\hline Anti-mouse lgG-488 & Goat & EarthOx & E032210-01 & $1: 200$ & ICC & $1 \mathrm{~h} 37^{\circ} \mathrm{C}$ \\
\hline DAPI & & Beyotime & $\mathrm{C} 1002$ & $1 ; 2000$ & ICC, IHC & $1 \mathrm{~min} \mathrm{RT}$ \\
\hline
\end{tabular}

\section{Morphological assessment}

The morphological assessment of astrocytes after OGD was performed according to M. Neal [43]. Briefly, $20 \times$ images (Olympus U-HGLGPS) were imported into ImageJ for morphological analysis. The glial processes could be analyzed using an ImageJ plugin named Analyze Skeleton [44]. The image was converted to binary and then skeletonized in ImageJ software, and then, the skeletonized image was put into the Analyze Skeleton plugin to get detailed information about the branch length of each cell. Cell soma size was measured by freehand selection outlining each cell soma and then selecting the "area" analyzes to measure. At least three fields were used for each section, and then, three biological replicates were used for each experiment. At least 20 cells were measured for each of the morphology assessments.

\section{Neurobehavioral testing}

Cliff aversion reaction, Geotaxis reflex and Grip test were respectively assessed at 1 day (P10), 3 days (P12), and 7 days (P16) after neonatal HI. All of the above experiments were observed by at least two uninformed laboratory workers, and all groups of animals maintained the same test method.

Cliff aversion reaction was used to assess the ability of rodents' respond to adverse environments [45]. Put two planks together and the board was $30 \mathrm{~cm}$ above the ground. The head and front upper limbs of the mouse were on the first plank, the rest of the body was on the second plank, and all the mice were placed in this position. When the mouse relaxed, the first plank was quickly lowered so that the bilateral forelimbs of the mouse were suddenly suspended. After a short delay, the mouse can return to the second plank. The time required for the mouse to withdraw the forelimb was examined. Each mouse was tested three times. If the forelimbs were not withdrawn for more than $60 \mathrm{~s}$, it would be recorded as $60 \mathrm{~s}$. Grip test was used to assess the performance and tolerance of mice [46]. The bilateral forelimbs of the mice were grasped on a metal wire
( $1.5 \mathrm{~mm}$ in diameter), the metal rope was $50 \mathrm{~cm}$ from the ground, and the ground was covered with cork. Record the time from the mouse holding the metal rope to releasing the metal rope and test each mouse three times.

Geotaxis reflex was considered to diagnose the function of vestibular and proprioception of mice [47]. A wooden board was placed at an angle of $45^{\circ}$, and then, the mouse was placed at the middle of the wood heading toward the lower end of the wood. The time required for the mouse to turn $180^{\circ}$ toward the upper end of the board was recorded. One mouse was tested three times. If the time was more than $60 \mathrm{~s}$, it would be regarded as the maximum value of $60 \mathrm{~s}$.

\section{Experimental design and statistical analysis}

Prism 7 (RRID: SCR_002798) software was used to analyze data and form the graphs in this work (including which tests were performed, exact $P$ values, and sample sizes). Simply, one-way ANOVA with a test for linear trend, Tukey test was used as appropriate to analyze parametric statistics. At least three independent experiments were applied to collect effective data. Bias was avoided by making sure that assessor was blinded to collecting and analyzing data. $P<0.05$ was considered significant. Average values represent the mean \pm SEM. In the quantitative analysis of Fig. $5 \mathrm{e}-\mathrm{g}$, the number of animals used in neurobehavioral testing was indicated in figure legends. "P represents the significance compared to sham or control. ${ }^{\#} P$ represents the significance compared to WT-HI or WT-OGD.

\section{Results}

TRPV1 deficiency prevents the upregulation of GFAP expression induced by neonatal $\mathrm{HI}$

To determine whether TRPV1 mediates astrocyte activation following neonatal $\mathrm{HI}$ insult, the expression of GFAP were investigated after neonatal $\mathrm{HI}$ in both TRPV1 KO mice and congenic WT C57BL/6 mice. Immunofluorescence staining revealed significantly stronger labeling of 
GFAP in the ipsilateral hippocampus at $12 \mathrm{~h}, 24 \mathrm{~h}$, and 48 $\mathrm{h}$ after neonatal $\mathrm{HI}$ compared to the sham group (Fig. 1a and Additional file 1: Figure S1A), and its expression saturated at $24 \mathrm{~h}$ (Fig. 1b, c). The labeling of Iba1 increased at $6 \mathrm{~h}, 12 \mathrm{~h}$, and $24 \mathrm{~h}$ (Additional file 1: Figure S1A). Western blot results (Fig. 1d, e) showed that GFAP protein level was gradually upregulated at $12 \mathrm{~h}, 24 \mathrm{~h}$, and $48 \mathrm{~h}$ after neonatal $\mathrm{HI}$ compared with the sham group, suggesting that $\mathrm{HI}$ insult significantly increases the number of activated astrocytes in the hippocampus.

On the other hand, immunofluorescence (Fig. 1f-h) and Western blot results (Fig. 1i, j) showed that the neonatal $\mathrm{HI}$-induced increase of GFAP expression was significantly reduced at $24 \mathrm{~h}$ in the TRPV1 $\mathrm{KO}$ mice compared with WT mice. Consistent with the genetic ablation result, systemic desensitization of TRPV1 (intraperitoneal injection

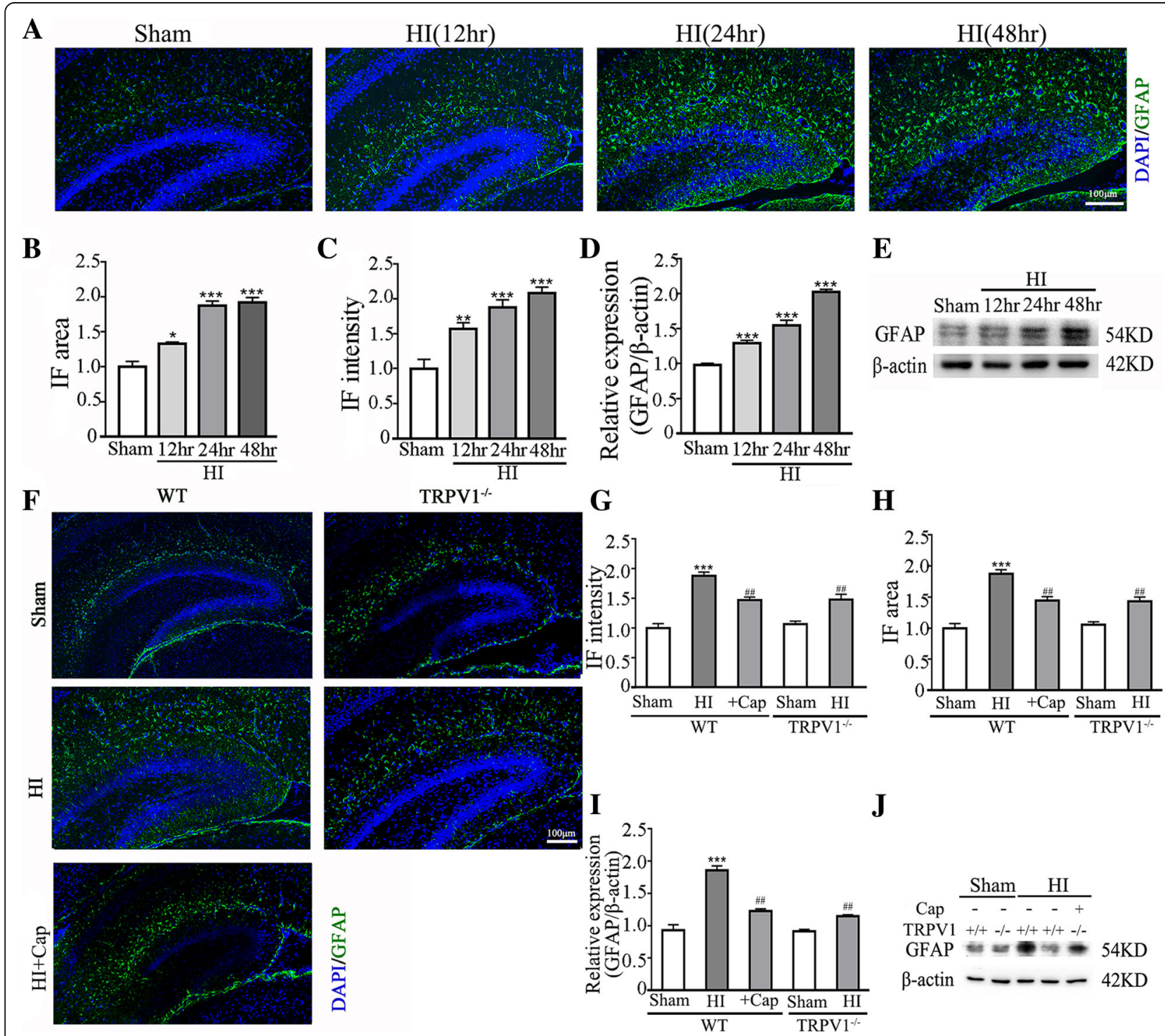

Fig. 1 Knocking out TRPV1 inhibited GFAP expression in hypoxia-ischemia brain tissue. a After HI, GFAP expression was upregulated at $12 \mathrm{~h}$, $24 \mathrm{~h}$, and $48 \mathrm{~h}$. GFAP expression levels by immunofluorescence were examined in the ipsilateral hemisphere sections from sham and HI groups. Scale bar $=100 \mu \mathrm{m}$. b, c Immunofluorescence intensity and cluster size of GFAP in the ipsilateral hemisphere hippocampus significantly increased in HI brain compared to sham brain. $n=6$ for each group. d, e Western blot revealed upregulated expression of GFAP at $12 \mathrm{~h}, 24 \mathrm{~h}$, and $48 \mathrm{~h}$. GFAP expression levels were examined in ipsilateral hemisphere sections from Sham and HI. Quantification of independent blots. $n=5$ for each group. f Knocking out TRPV1 or pretreating capsaicin reduced the upregulation of GFAP as shown by immunofluorescence at $24 \mathrm{~h}$. Scale bar $=100 \mu \mathrm{m}$. g, h Knocking out TRPV1 or pretreating capsaicin reduced immunofluorescence intensity and cluster size of GFAP compared to HI group. $n=6$ for each group. $\mathbf{i}$, $\mathbf{j}$ Western blot revealed that knocking out TRPV1 or pretreating capsaicin reduced GFAP upregulation compared to HI group. Quantification of independent blots. $n=5$ for each group. Cap, $3 \mathrm{mg} / \mathrm{kg}$ capsaicin. Average values represent the mean \pm SEM. ${ }^{*} P<0.05$, ${ }^{* *} P<0.01$, ${ }^{* * *} P<0.001$ versus sham (Tukey's test after one-way ANOVA). ${ }^{* \#} P<0.001$ versus WT-HI (Tukey's test after one-way ANOVA) 
of $3 \mathrm{mg} / \mathrm{kg}$ capsaicin $0.5 \mathrm{~h}$ before neonatal $\mathrm{HI}$ ) significantly reduced the increase of GFAP expression caused by neonatal HI in WT mice [48-50]. Knocking out TRPV1 mildly reduced $\mathrm{Iba}^{+}$cell, while intensely reduced $\mathrm{GFAP}^{+}$cell in the ipsilateral hemisphere hippocampus (Additional file 1: Figure S1). Taken together, these results suggest that either genetic ablation of TRPV1 or systemic desensitization of TRPV1 effectively suppress the upregulation of GFAP expression induced by neonatal $\mathrm{HI}$, highlighting the importance of TRPV1 in neonatal HI-induced astrocyte activation.

\section{Activation of astrocytes and increased expression of inflammatory cytokines induced by OGD are TRPV1- dependent}

To explore the role of TRPV1 on HI-induced activation of astrocytes in vitro, hippocampal astrocytes were isolated and cultured to undergo OGD. Either TRPV1 deficiency or capsaicin-induced TRPV1 desensitization, pretreating with capsaicin $(10 \mu \mathrm{M}) 0.5 \mathrm{~h}$ before OGD, prevented astrocytes from cellular edema (Fig. 2a, b), reduction of branch processes (Fig. 2a, c), and cell death (Fig. 2d) at $24 \mathrm{~h}$ after OGD. In addition, the upregulation of GFAP reduced in TRPV1 deficiency astrocytes and WT capsaicin pretreatment astrocytes (Fig. 2e, f).

Activated astrocytes release several cytokines in neurological diseases [9]. OGD challenge significantly increased IL-1ß (Fig. 2g), IL-6 (Fig. 2h), and TNF (Fig. 2i) mRNA expression level, which was inhibited by genetic ablation and capsaicin-induced desensitization of TRPV1 (Fig. 2g-i). Of note, although the expression level of the anti-inflammatory cytokine (IL-10) increased after OGD, genetic ablation and capsaicin-induced desensitization of TRPV1 only slightly inhibited the upregulation (Fig. 2j). These results suggested that TRPV1 is required for astrocyte activation, morphological change, and the expression of pro-inflammatory cytokines, especially IL- $1 \beta$ and IL-6 in vitro.

\section{Activation of JAK2-STAT3 signaling in astrocytes is required for OGD-induced TRPV1-dependent expression of IL-1 $\beta$}

TRPV1 activation has been shown to exacerbate neuro-inflammatory actions by activating pro-inflammatory STAT3 signaling [29]. Thus, Western blot was used to confirm whether TRPV1 activated JAK2-STAT3 signaling at 24h after OGD. Western blot results showed that phosphorylation of STAT3 and JAK2 were significantly increased after OGD, which was reversed by either genetic ablation or capsaicin-induced desensitization of TRPV1 (Fig. 3a-c), indicating the critical role of TRPV1 on the phosphorylation of JAK2 and STAT3. Next, we used Stattic, a specific inhibitor of STAT3 phosphorylation, to investigate whether pharmacological inhibition of STAT3 phosphorylation attenuates or abolishes TRPV1-induced increase of GFAP expression.
Indeed, treating WT astrocytes with Stattic $(5 \mu \mathrm{M})$ during OGD challenge significantly reduced the expression of GFAP. In marked contrast, Stattic did not inhibit the expression of GFAP in TRPV1 deficiency astrocytes (Fig. 3d-f).

Recent studies have shown that JAK2-STAT3 signaling was vital for the expression of IL-1 $\beta$ in both resident macrophages [51] and CNS microglia [32], and expression of IL- $1 \beta$ has been used to predict the severity of HIE in infants [12]. Therefore, we next verified the role of TRPV1-activated JAK2-STAT3 signaling in OGD-induced IL-1 $\beta$ upregulation in astrocytes. As shown in Fig. $3 g$, h, mRNA transcripts and protein level of IL- $1 \beta$ were downregulated by inhibiting the phosphorylation of STAT3 in WT astrocytes and Stattic did not inhibit the expression of IL-1 $\beta$ in TRPV1 deficiency astrocytes. These results suggested that TRPV1 promoted the activation of astrocytes and the expression of IL-1 $\beta$ via JAK2-STAT3 signaling after OGD challenge.

\section{Activation of NLRP3 inflammasome in astrocytes is required for OGD-induced TRPV1-dependent release of IL-1 $\beta$}

The activation of NLRP3 inflammasome was critical for IL-1 $\beta$ release in multiple sclerosis (MS), stroke, and Alzheimer's disease [52]. Following OGD challenge, the levels of mRNA transcripts of NLRP3 inflammasome components (NLRP3, ASC, and caspase-1) increased and the increasing was attenuated by genetic ablation and capsaicin-induced desensitization of TRPV1 (Fig. 4a-c).

ASC is a key adaptor of several inflammasomes including NLRP3 and AIM2, and their activation is reflected by ASC speck assembly or oligomerization [53]. The confocal imaging is used to measure the assembly of ASC speck indicated by the white arrow (Fig. 4d). Upon NLRP3 activation by OGD challenge the dispersed ASC condenses into a large speck in astrocytes, genetic ablation or capsaicin-induced desensitization of TRPV1 reduced ASC oligomerization (Fig. $4 d$, e). Immunofluorescent staining showed increased intensity (Fig. 4f-h) and co-localization (Fig. 4i) of NRLP3 and caspase-1 after OGD, which were reduced by either genetic ablation of TRPV1 or capsaicin-induced desensitization of TRPV1, suggesting that TRPV1 mediates the release of IL-1 $\beta$ following OGD challenge by activation of NLRP3 inflammasome in astrocytes.

\section{Brain damage and neurobehavioral disorders induced by} neonatal $\mathrm{HI}$ are reduced in TRPV1 KO mice

IL-1 $\beta$ is the key mediator of neuroinflammation in the CNS [54], and the upper results show that TRPV1 is critical to astrocyte activation and release of astrocyte-derived inflammatory cytokines. To investigate whether the TRPV1-dependent inflammatory response could be translated into brain damage in vivo, we examined brain damage $24 \mathrm{~h}$ after neonatal $\mathrm{HI}$ in TRPV1 KO mice or WT mice subjected to capsaicin pretreatment. As shown in 


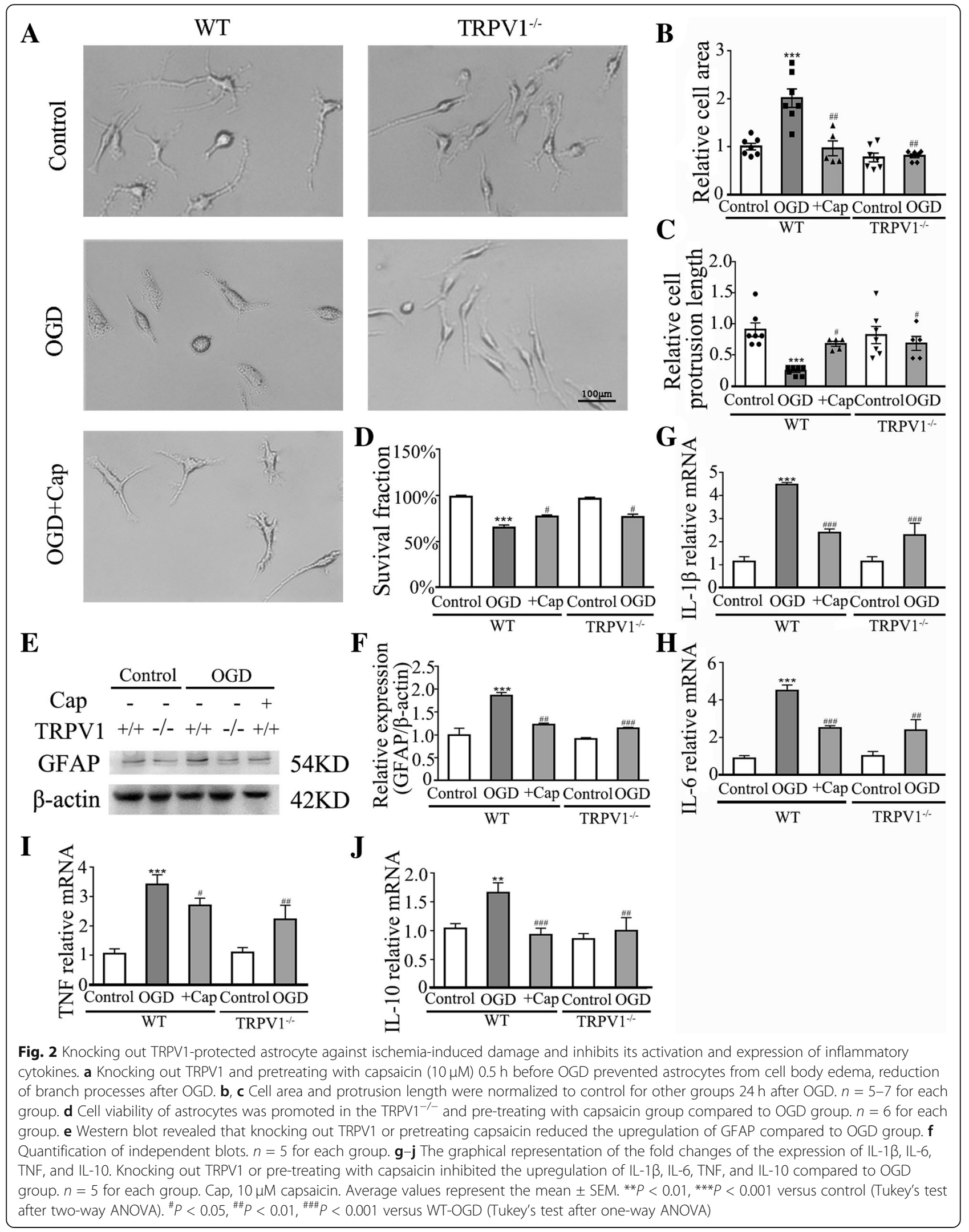




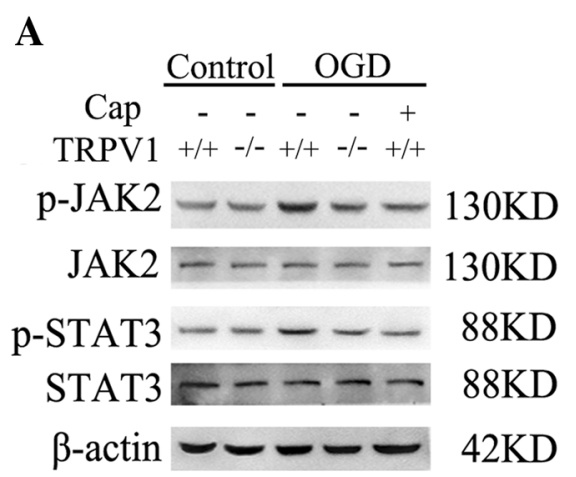

B

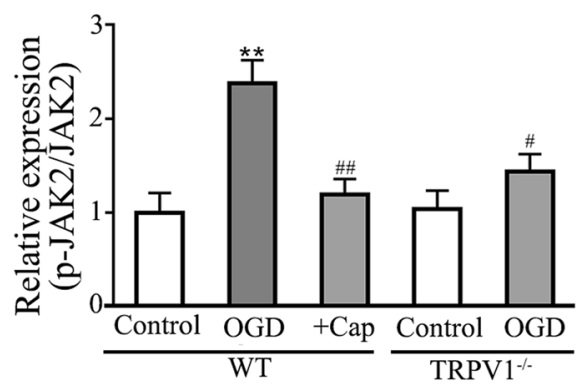

$\mathbf{C}$

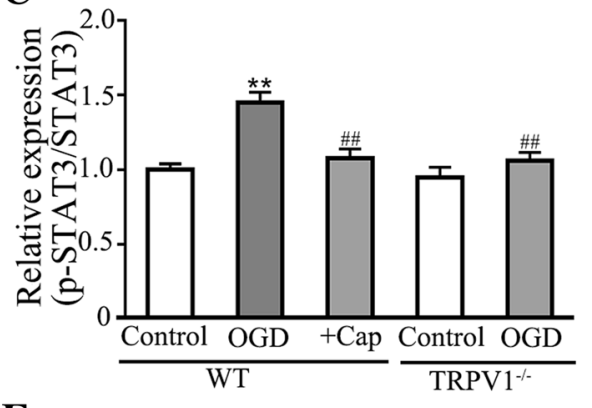

D

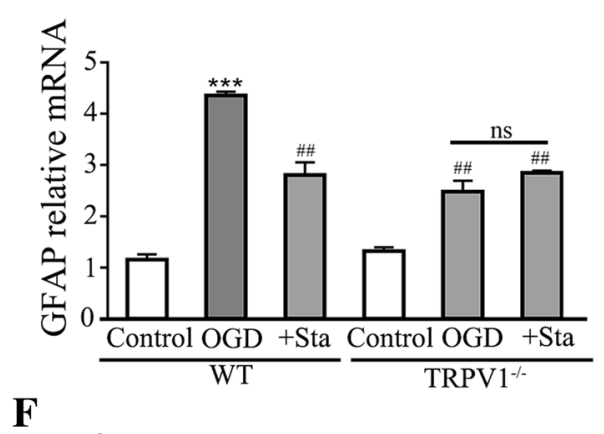

$\mathbf{E}$

$\mathbf{F}$

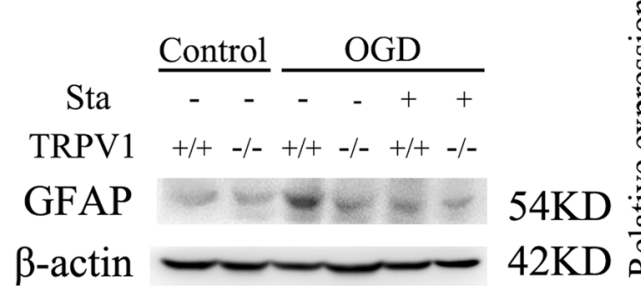

G

$\mathbf{H}$
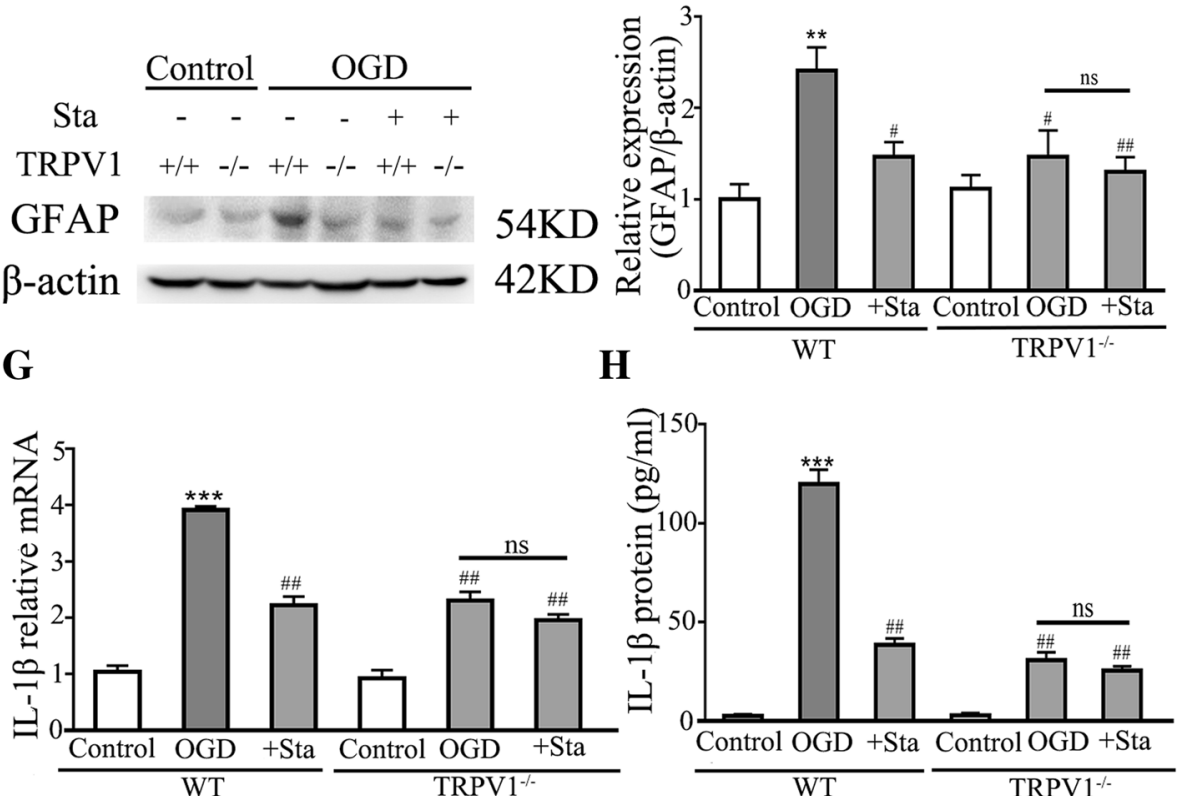

Fig. 3 Knocking out TRPV1 inhibited the phosphorylation of JAK2 and STAT3, astrocytes activation, and the expression of IL-1 $\beta$. a Western blot analysis showed the upregulated after OGD, and knocking out TRPV1 or pretreating with capsaicin inhibited the phosphorylation of JAK2 and STAT3 compared to OGD group. b, $\mathbf{c}^{\#} P<0.05$ (Tukey's test after two-way repeated-measures ANOVA). $n=5$ for each group. $\mathbf{d}$ The graphical representation of the fold changes of the expression of GFAP, treating with Stattic $(5 \mu \mathrm{M})$ inhibited the upregulation of GFAP. $n=5$ for each group. e Western blot revealed treating with Stattic $(5 \mu \mathrm{M})$ inhibited the upregulation of GFAP. $n=5$ for each group. $\mathbf{f}$ As confirmed by quantification of independent blots. ${ }^{\#} P<0.05$ (Tukey's test after two-way repeated-measures ANOVA). $n=5$ for each group. $\mathbf{g}, \mathbf{h}$ The graphical representation of the fold changes of IL-1 $\beta$. Treating with Stattic $(5 \mu \mathrm{M})$ inhibited the upregulation of IL-1 $\beta . n=6$ for each group. Cap, $10 \mu \mathrm{M}$ capsaicin. Sta, $5 \mu$ M stattic. Average values represent the mean \pm SEM. ${ }^{* *} P<0.01,{ }^{* * *} P<0.001$ versus control (Tukey's test after one-way ANOVA). ${ }^{\#} P<0.05,{ }^{\# \#} P<0.01$ versus WT-OGD (Tukey's test after one-way ANOVA). ns $P>0.05$ (Tukey's test after one-way ANOVA) 

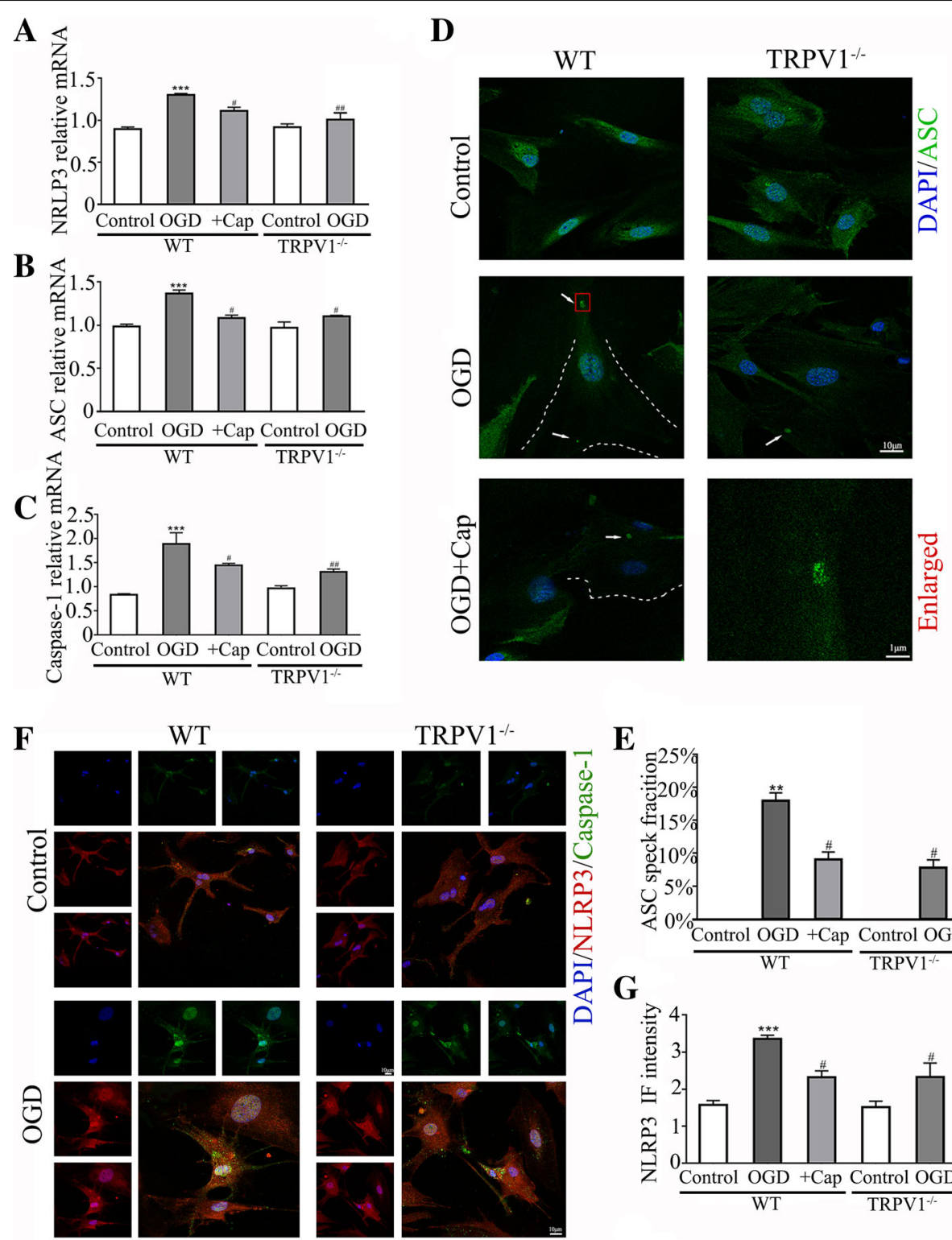

$\mathbf{E}$
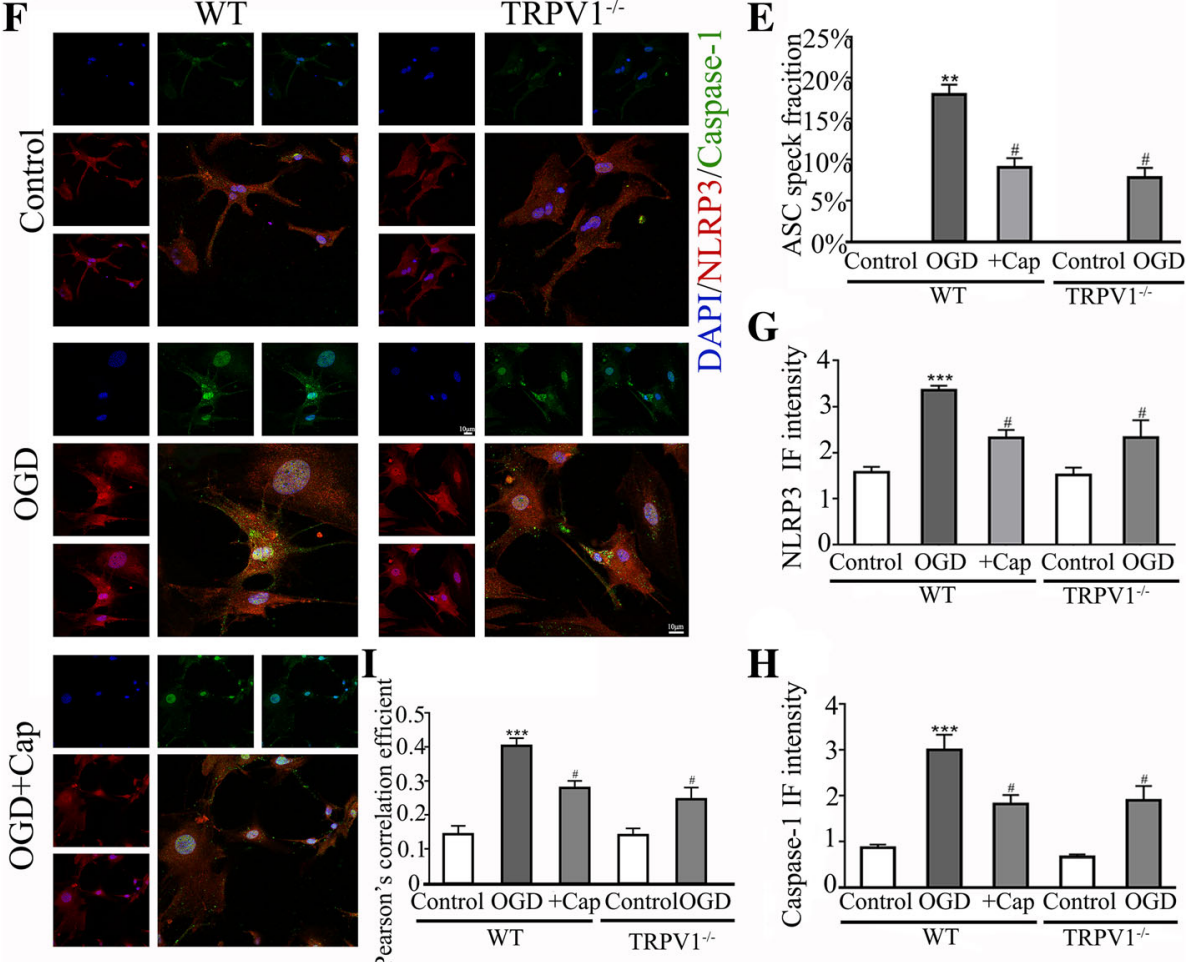

$\mathbf{G}$
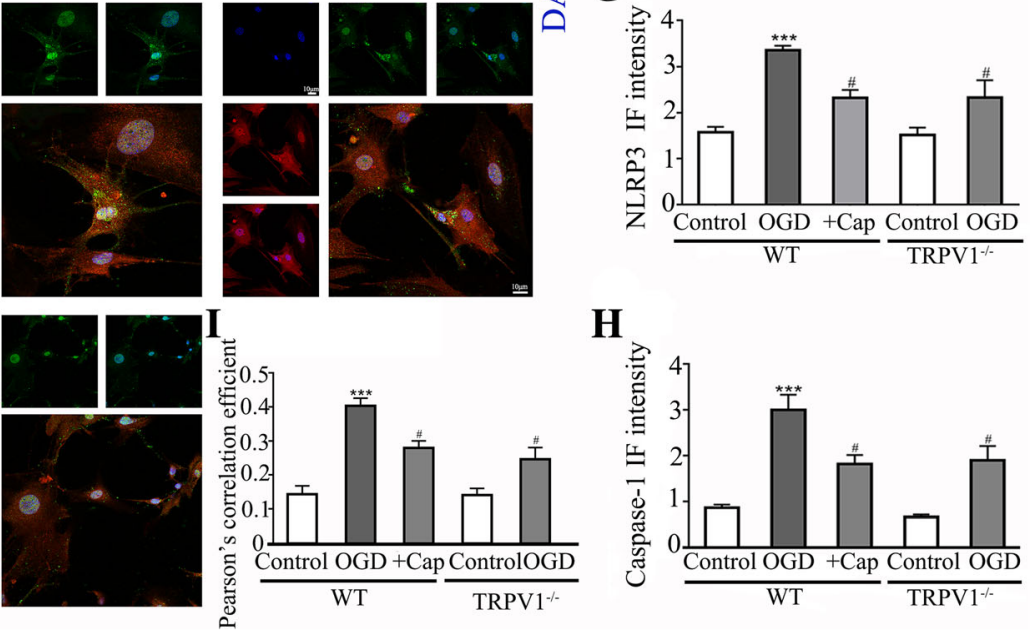

$\mathbf{H}$

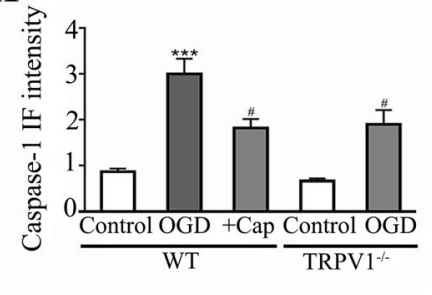

Fig. 4 (See legend on next page.) 
(See figure on previous page.)

Fig. 4 Knocking out TRPV1 attenuates the formation of NLRP3 inflammasome. a-c The graphical representation of the fold changes of NLRP3, ASC, and caspase-1. Knocking out TRPV1 or pretreating with capsaicin reduced the upregulation of NLRP3, ASC, and caspase-1 compared to OGD group. $n=5$ for each group. $\mathbf{d}$ Confocal images showed ASC specks increased after OGD, and knocking out TRPV1 or pretreating with capsaicin inhibited the increase of ASC specks compared to OGD group. White arrows indicate ASC specks and the scale bar $=10 \mu \mathrm{m}$, scale bar $=1 \mu \mathrm{m}$ for the enlarged image. e ASC speck positive astrocytes percentage was determined in 10 fields/well and divided by the number of cells counterstained with DAPI. $n=4$ for each group. $\mathbf{f}$ Confocal images showed that NLRP3 and caspase-1 were increased after OGD, and knocking out TRPV1 or pretreating with capsaicin inhibited their upregulation compared to OGD group. Scale bar $=10 \mu \mathrm{m} . \mathbf{g}, \mathbf{h}$ The intensity of NLRP3 and caspase-1 fluorescence was determined in 10 fields/well and divided by the number of cells counterstained with DAPI. $n=4$ for each group. $\mathbf{i}$ Pearson's correlation coefficient is shown in the graph from the analysis of independent experiments. $n=4$ for each group. Cap, $10 \mu \mathrm{M}$ capsaicin. Average values represent the mean \pm SEM. ${ }^{* *} P<0.01$, ${ }^{* * *} P<0.001$ versus control (Tukey's test after one-way ANOVA). ${ }^{\#} P<0.05,{ }^{\#} P<0.01$ versus WT-OGD (Tukey's test after one-way ANOVA)

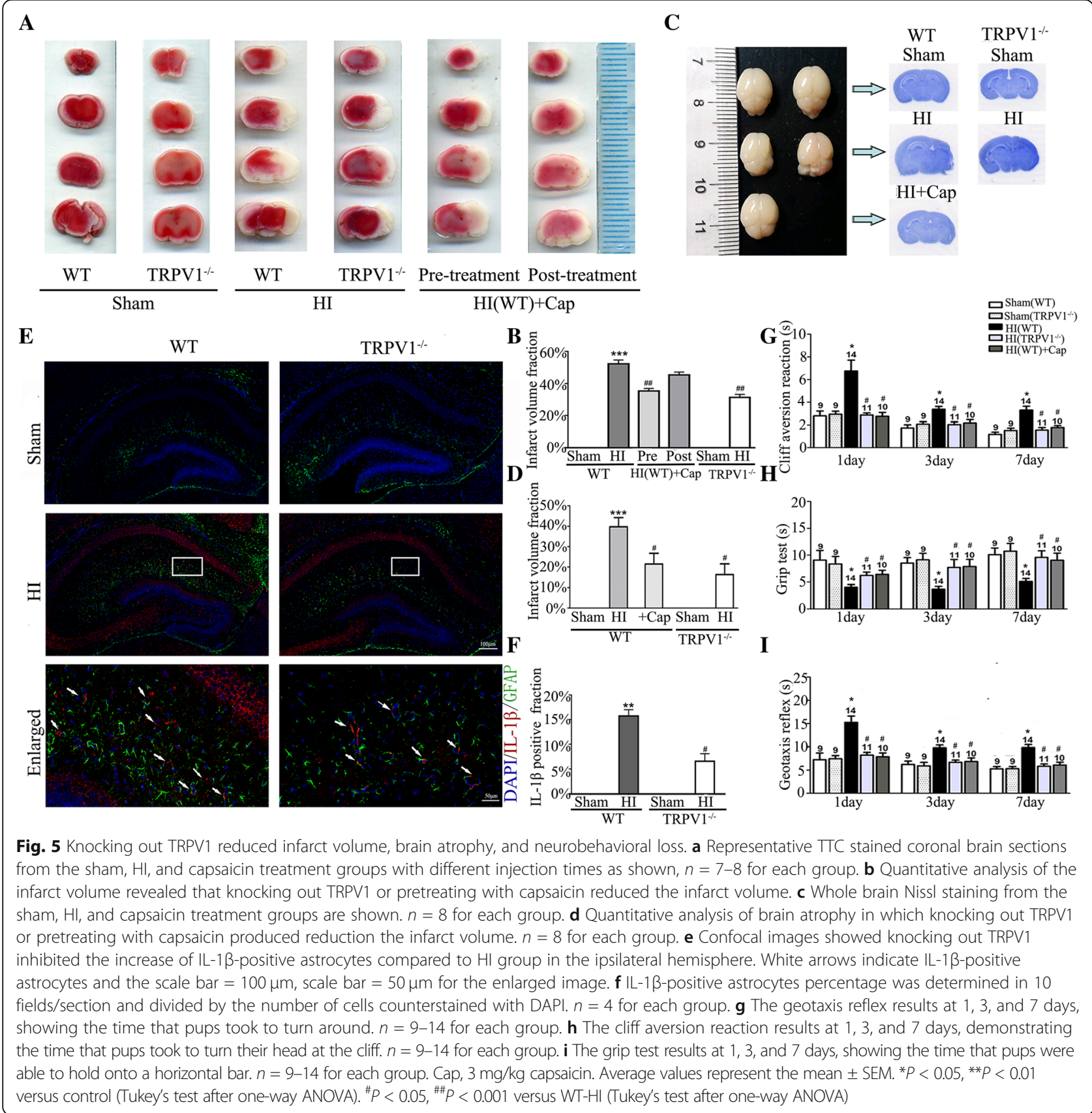


Fig. 5a, b, the TTC-negative area in the ipsilateral hemisphere was significantly decreased in TRPV1 KO mice and WT mice pretreated with capsaicin (intraperitoneal injection $3 \mathrm{mg} / \mathrm{kg} 0.5 \mathrm{~h}$ before neonatal $\mathrm{HI}$ ). In marked contrast, post-treating with capsaicin $(3 \mathrm{mg} / \mathrm{kg}$, administered 5 min after neonatal $\mathrm{HI}$ ) did not effectively reduce the TTC-negative area in WT mice (Fig. 5a, b). Next, we used whole-brain Nissl staining to determine the role of TRPV1 in brain atrophy $24 \mathrm{~h}$ post neonatal HI (Fig. 5c, d). Neonatal HI produced marked brain atrophy compared with the ipsilateral side of the sham group. Brain atrophy in either TRPV1 KO mice or WT capsaicin pre-treatment mice is significantly reduced. Immunofluorescence showed that the number of IL-1 $\beta$-positive astrocytes in the ipsilateral hemisphere hippocampus (indicated by the white arrow) decreased in TRPV1 KO mice compared with WT mice after neonatal HI (Fig. 5e, f).

To investigate whether TRPV1 is involved in neonatal HI-induced neurobehavioral disorders, three different neurobehavioral tests including cliff aversion reaction (Fig. 5g), grip test (Fig. 5h) and geotaxis reflex (Fig. 5i) were used. Neonatal HI significantly prolonged the time for WT pups to turn around in the cliff aversion reaction, reduced the holding time in the grip test, and increased the head-turning time in the geotaxis reflex at days 1,3 , and 7 compared with the sham group, which was recovered in TRPV1 KO and WT capsaicin pretreatment mice. These results suggest that TRPV1 contributes to brain atrophy, infarct size, and loss of reflexes and motor ability caused by neonatal HI.

\section{Discussion}

Both astrocytes and microglia were activated after injury by pro-inflammatory mediators, cytokines, and ROS that are secreted by injured neurons and glial cells [55]. The role of microglia in HIE was well established and microglial activation and aggregation had become one of the hallmarks for HIE in human infants [3, 56-58]. Notably, astrocytes are also involved in the pathogenesis of neurological diseases and sterile inflammatory responses $[4,9,59]$ and the role of astrocytes in CNS inflammatory was controversial (both detrimental and beneficial) in brain ischemia [3]. Early studies have extensively focused on the protective effects of astrocytes, such as the isolation of the damaged area from the rest of the CNS tissue and reconstruction of the compromised blood-brain barrier $[60,61]$. Recent studies, however, demonstrated that astrocytes have a detrimental role in response to ischemic stress [4, 10, 62-64].

Ion channels (kv4.1, kv1.3, TRPV1, TRPM7, NKCC1...) and intracellular ion homeostasis $\left(\mathrm{K}^{+}, \mathrm{Na}^{+}, \mathrm{Ca}^{2+}\right.$, and $\left.\mathrm{Cl}^{-}\right)$ are critical for glia proper functions in CNS [65-67]. TRPV1 that is mainly permeable to $\mathrm{Ca}^{2+}$ naturally expresses in the endomembrane system of microglia and astrocytes which plays important roles in astrocyte and microglial activation [68-70]. It has been proved that overactivated TRPV1 increase NADPH oxidase-mediated reactive oxygen species (ROS) generation [71, 72], mitochondrial disruption [73] in microglia, and microglia-induced inflammation [74]. TRPV1 also accelerate astrocyte and microglial migration and chemotaxis during stress by directly interacting with cytoskeletal elements $[75,76]$. The role of TRPV1 in microglia is well explored [26], while its distinctive function in astrocyte is not fully understood in a variety of neuroimmune diseases.

In the present study, we showed that during the subacute phase of HI $(24 \mathrm{~h})$, astrocyte and microglia were overactivated and microglia activation is about $3 \mathrm{~h}$ earlier than astrocyte. This may because microglia acting as the constant sensors of changes in the CNS microenvironment is more sensitive to insults [77]. TRPV1, which is activated after ischemia [78] intensely mediate astrocyte activation compared to microglia, increases IL-1 $\beta$ release and exacerbates ischemia-induced brain damage (brain atrophy, infarct size, and neurobehavioral loss). TRPV1 is required for the phosphorylation of JAK2 and STAT3 which promotes the transcription of GFAP and IL-1 $\beta$. TRPV1 function is critical for the activation of NLRP3 inflammasome which promotes the cleavage of pro-IL-1 $\beta$ (Fig. 6). Our studies reveal a previously unknown function of astrocytic TRPV1 and potentially identify a critical target for the treatment of CNS inflammation.

Injured cortex becomes hypertrophic in many types of CNS disorders such as stroke and neurotrauma, which is often accompanied with the upregulation of GFAP in astrocytes [9]. As expected, we found that GFAP expression increased in a time-dependent manner after neonatal HI, which is mediated by TRPV1 as either genetic ablation or capsaicin-induced systemic desensitization of TRPV1 inhibited the upregulation of GFAP. In vitro studies further confirmed that TRPV1 directly regulates the function of astrocytes in a cell autonomous manner without the requirement of neurons or microglia, since inhibition of TRPV1 function prevented astrocytes from cellular edema, reduction of branch processes, cell death, and excessive activation caused by OGD challenge.

The role of activated astrocytes has been reported in the sterile inflammatory response and the release of several cytokines, such as IL-1 $\beta$, IL-6, and TNF [79] in middle cerebral artery occlusion (MCAO). Our previous work demonstrated that TRPV1 activation promotes the expression of TNF, IL-1 $\beta$, IL-6, and high mobility group box 1 (HMGB1) in repetitive febrile seizure (FS) mice [36]. Consistent with these observations, we found that TRPV1 is required for OGD-induced upregulation of IL-1 $\beta$, IL-6, and TNF in astrocytes. Interestingly, IL-10 mRNA transcript was slightly increased in a TRPV1-dependent manner after neonatal $\mathrm{HI}$, which might be caused by a negative 


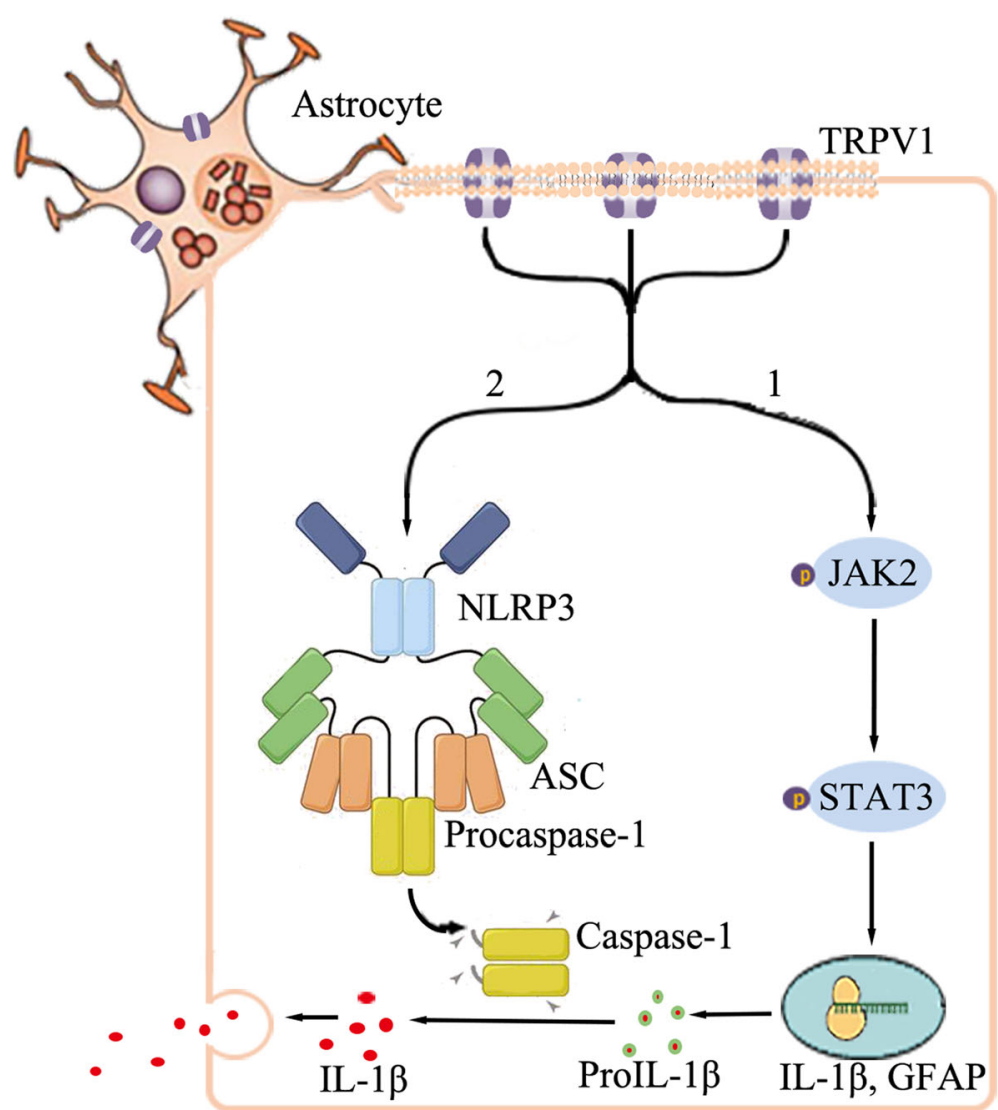

Fig. 6 Schematic illustration of the proposed mechanism. TRPV1 plays an important role in neonatal HI-induced astrocytes activation and the transcription and post-translational protein modification of IL-1 $\beta$. (1) TRPV1 stimulated the phosphorylation of JAK2, and phosphorylated JAK2 promoted the phosphorylation of STAT3. And activated STAT3 bound to its target genes (GFAP and IL-1B) and upregulated their expression. (2) TRPV1 promoted the formation of NLRP3 inflammasome (NLRP3, ASC, and caspase-1), which mediated the activation of caspase-1 and then stimulated the cleavage of pro-IL-1 $\beta$

feedback from the astrocytes induced by severe inflammatory responses $[80,81]$.

How does TRPV1 mediate astrocyte activation and upregulation of pro-inflammatory cytokines? Previous researches demonstrated that the JAK2-STAT3 pathway is involved in the activation of astrocytes and the expression of cytokines both in vivo and in vitro [30-32]. Moreover, in inflammatory signaling cascades in the brain, TRPV1 has been shown to exacerbate neuro-inflammatory actions by activating pro-inflammatory STAT3 signaling [29]. Inhibition STAT3 phosphorylation via JAK2-blockade reduces neonatal HI-induced neuroinflammation and tissue loss [82]. Consistent with these studies, we found that TRPV1 promoted the phosphorylation of JAK2 and STAT3 induced by OGD challenge. Moreover, a specific inhibitor of STAT3 (Stattic) significantly reduced the expression of GFAP and IL-1 $\beta$ following OGD challenge in a TRPV1-dependent manner. These results suggest that TRPV1 mediates the activation of astrocytes and the expression of IL- $1 \beta$ via the JAK2/STAT3 pathway.
IL-1 $\beta$ in umbilical and peripheral blood is noteworthy upregulated in children suffered from HIE, and its expression level corresponds to the grades and adverse outcomes of HIE [83]. The release of IL-1 $\beta$ depends on the activation of NLRP3 inflammasome which cleaves the pro-inflammatory cytokines IL- $1 \beta$ to its active form by mediating the activation of caspase- $1[15,84,85]$. It has been proved that, in other disease models such as intracerebral hemorrhage model, ischemia/reperfusion injury model, and hemorrhage transgenic amyotrophic lateral sclerosis model, NLRP3 inflammasome is activated in astrocytes [16-19]. In the present study, the activation of NLRP3 inflammasome followed by IL-1 $\beta$ releasing increased after OGD challenge. And inhibition of TRPV1 blocked this modification, suggesting that TRPV1 drives the release of IL- $1 \beta$ by stimulating the activation of NLRP3 inflammasome after OGD in astrocytes.

In vivo, hampered TRPV1 function significantly reduced brain atrophy, infarct size, and the number of IL- $1 \beta$-positive astrocytes in the hippocampus. Additionally, the recovery of neurobehavioral disorders indicated 
by three independent neurobehavioral developmental tests (the geotaxis reflex, cliff aversion reaction, and grip test) after neonatal HI was potentiated in TRPV1 KO mice. Our results suggest that astrocytic TRPV1 is required for the exacerbation of the brain damage and neurobehavioral disorders after neonatal HI. Of note, since TRPV1 do express by microglia/macrophages, neuron [78], and neutrophils [86], these types of cells might contribute to the detrimental effects mediated by TRPV1 independently or cooperatively in HIE. Future studies using cell-specific TRPV1 knockdown/knockout mice needed to confirm this possibility.

\section{Conclusion}

TRPV1 promotes activation of astrocytes and release of astrocyte-derived IL-1 $\beta$ mainly via JAK2-STAT3 signaling and activation of the NLRP3 inflammasome. Our findings provide mechanistic insights into TRPV1-mediated brain damage and neurobehavioral disorders caused by neonatal $\mathrm{HI}$ and potentially identify astrocytic TRPV1 as a novel therapeutic target for treating HIE in the subacute stages $(24 \mathrm{~h})$.

\section{Additional file}

Additional file 1: Knocking out TRPV1-reduced GFAP and Iba-1-positive cell in hypoxia-ischemia brain tissue. (A) GFAP and Iba-1-positive cell were examined in the ipsilateral hemisphere sections from Sham and $\mathrm{HI}$ groups. Scale bar $=100 \mu \mathrm{m}$. (B, C) The number of GFAP and Iba-1-positive cell in the ipsilateral hemisphere hippocampus. $n=6$ for each group. Average values represent the mean \pm SEM. ${ }^{*} P<0.05,{ }^{* *} P<0.01$, ${ }^{* *} P<0.001$ (Tukey's test after one-way ANOVA and two-way ANOVA). (TIF $8629 \mathrm{~kb}$ )

\section{Abbreviations \\ HI: Hypoxia-ischemia; TRPV1: Transient receptor potential vanilloid 1; GFAP: Glial fibrillary acidic protein; Iba1: lonized calcium-binding adapter molecule 1; JAK2: Janus kinase 2; STAT3: Signal transducer and activator of transcription 3; NLRP3: Nucleotide-binding, oligomerization domain (NOD)- like receptor pyrin domain-containing protein 3; ASC: Apoptosis-associated speck-like protein containing carboxyl-terminal CARD; HIE: Hypoxic-ischemic encephalopathy; FS: Febrile seizure; DAPI: 4:6-Diamidino-2-phenylindole; IL- 1ß: Interleukin 13; IL-6: Interleukin 6; OGD: Oxygen-glucose deprivation; PBS: Phosphate-buffered saline; TNF: Tumor necrosis factor; IL-10: Interleukin 10; TTC: 2, 3, 5-Triphenyltetrazolium chloride monohydrate; PMSF: Phenylmethanesulfonyl fluoride; PVDF: Polyvinylidene fluoride; BSA: Bovine serum albumin; ROS: Reactive oxygen species}

\section{Acknowledgements}

We thank Meng-Liu Zeng for critically reading and revising the manuscript. We sincerely thank Jun-Chen Liu, Wen-Di Luo, and Jian-Yu Wu for their valuable comments and for the technical assistance during the experiments.

\section{Funding}

This research is supported by the Natural Science Foundation of China (Grant No. 81571481, No. 81370737, and No. 81601325) and Independent Scientific Research Project Fund of Wuhan University (No. 2042017kf0066).

\section{Availability of data and materials}

All raw data used in this manuscript are available from the corresponding author on reasonable request.

\section{Authors' contributions}

$Y X L, P B W, H X H$, and $W X$ conceived and designed the experiments. $Y X L, W X$, MJW, and JGT performed the experiments. YXL, WX, and $S L$ analyzed the data. $H X H, L W H, M X Y$, and HWX contributed to the reagents/materials/ analysis tools. $Y X L, W X$, and PBW wrote the paper. All authors reviewed and approved the final manuscript.

\section{Ethics approval and consent to participate}

All animals used in experiments were provided by the Nanjing Biomedical Research Institute and the Hubei Province Center for Animal Experiments. And animal experiments were approved by the Care and Use Committee of Wuhan University Medical School.

\section{Consent for publication}

Not applicable.

\section{Competing interests}

The authors declare that they have no competing interests.

\section{Publisher's Note}

Springer Nature remains neutral with regard to jurisdictional claims in published maps and institutional affiliations.

\section{Author details}

${ }^{1}$ Department of Physiology, Hubei Provincial Key Laboratory of Developmentally Originated Disorder, School of Basic Medical Sciences, Wuhan University, Donghu Rd185\#, Wuhan 430071, Hubei, China. ${ }^{2}$ No.1 Middle School affiliated to Central China Normal University, Wuhan, China. ${ }^{3}$ Department of Pathophysiology, School of Basic Medical Sciences, Wuhan University, Wuhan, China. ${ }^{4}$ Department of Immunology, School of Basic Medical Sciences, Wuhan University, Wuhan, China. ${ }^{5}$ Department of Pathology, Renmin Hospital of Wuhan University, Jiefang Rd238\#, Wuhan 430071, Hubei, China.

Received: 15 January 2019 Accepted: 25 April 2019

Published online: 29 May 2019

\section{References}

1. Confortim HD, Deniz BF, de Almeida W, Miguel PM, Bronauth L, Vieira MC, de Oliveira BC, Pereira LO. Neonatal hypoxia-ischemia caused mild motor dysfunction, recovered by acrobatic training, without affecting morphological structures involved in motor control in rats. Brain Res. 2019; 1707:27-44

2. Zaitoun IS, Cikla U, Zafer D, Udho E, Almomani R, Suscha A, Cengiz P, Sorenson CM, Sheibani N. Attenuation of retinal vascular development in neonatal mice subjected to hypoxic-ischemic encephalopathy. Sci Rep. 2018;8:9166

3. Liu F, McCullough LD. Inflammatory responses in hypoxic ischemic encephalopathy. Acta Pharmacol Sin. 2013;34:1121-30.

4. Seifert G, Schilling K, Steinhauser C. Astrocyte dysfunction in neurological disorders: a molecular perspective. Nat Rev Neurosci. 2006;7:194-206.

5. Swanson RA, Ying W, Kauppinen TM. Astrocyte influences on ischemic neuronal death. Curr Mol Med. 2004:4:193-205.

6. Habbas S, Santello M, Becker D, Stubbe H, Zappia G, Liaudet N, Klaus FR, Kollias G, Fontana A, Pryce CR, et al. Neuroinflammatory TNFalpha impairs memory via astrocyte signaling. Cell. 2015;163:1730-41.

7. Sirko S, Irmler M, Gascon S, Bek S, Schneider S, Dimou L, Obermann J, De Souza Paiva D, Poirier F, Beckers J, et al. Astrocyte reactivity after brain injury: the role of galectins 1 and 3. Glia. 2015;63:2340-61.

8. Blakely PK, Hussain S, Carlin LE, Irani DN. Astrocyte matricellular proteins that control excitatory synaptogenesis are regulated by inflammatory cytokines and correlate with paralysis severity during experimental autoimmune encephalomyelitis. Front Neurosci. 2015;9:344.

9. Pekny M, Pekna M, Messing A, Steinhauser C, Lee JM, Parpura V, Hol EM, Sofroniew MV, Verkhratsky A. Astrocytes: a central element in neurological diseases. Acta Neuropathol. 2016;131:323-45.

10. Villapol S, Gelot A, Renolleau S, Charriaut-Marlangue C. Astrocyte responses after neonatal ischemia: the yin and the yang. Neuroscientist. 2008;14:339-44. 
11. Li X, Zhao H, Tan X, Kostrzewa RM, Du G, Chen Y, Zhu J, Miao Z, Yu H, Kong J, Xu X. Inhibition of connexin43 improves functional recovery after ischemic brain injury in neonatal rats. Glia. 2015;63:1553-67.

12. Chen X, Sadowska GB, Zhang J, Kim JE, Cummings EE, Bodge CA, Lim YP, Makeyev O, Besio WG, Gaitanis J, et al. Neutralizing anti-interleukin-1beta antibodies modulate fetal blood-brain barrier function after ischemia. Neurobiol Dis. 2015;73:118-29.

13. Jones ME, Lebonville CL, Paniccia JE, Balentine ME, Reissner KJ, Lysle DT. Hippocampal interleukin-1 mediates stress-enhanced fear learning: a potential role for astrocyte-derived interleukin-1 beta. Brain Behav Immun. 2018;67:355-63.

14. Schultz J, Schwarz A, Neidhold S, Burwinkel M, Riemer C, Simon D, Kopf M, Otto M, Baier M. Role of interleukin-1 in prion disease-associated astrocyte activation. Am J Pathol. 2004;165:671-8.

15. Mezzasoma L, Antognelli C, Talesa VN. Atrial natriuretic peptide down-regulates LPS/ATP-mediated IL-1 beta release by inhibiting NF-kB, NLRP3 inflammasome and caspase-1 activation in THP-1 cells. Immunol Res. 2016;64:303-12.

16. Ren H, Kong Y, Liu Z, Zang D, Yang X, Wood K, Li M, Liu Q. Selective NLRP3 (pyrin domain-containing protein 3) inflammasome inhibitor reduces brain injury after intracerebral hemorrhage. Stroke. 2018;49:184-92.

17. Guo Z, Yu S, Chen X, Ye R, Zhu W, Liu X. NLRP3 is involved in ischemia/ reperfusion injury. CNS Neurol Disord Drug Targets. 2016;15:699-712.

18. Gugliandolo A, Giacoppo S, Bramanti P, Mazzon E. NLRP3 inflammasome activation in a transgenic amyotrophic lateral sclerosis model. Inflammation. 2018;41:93-103.

19. Zhou K, Enkhjargal B, Xie Z, Sun C, Wu L, Malaguit J, Chen S, Tang J, Zhang J, Zhang JH. Dihydrolipoic acid inhibits lysosomal rupture and NLRP3 through lysosome-associated membrane protein-1/calcium/calmodulindependent protein kinase II/TAK1 pathways after subarachnoid hemorrhage in rat. Stroke. 2018:49:175-83.

20. Chen D, Dixon BJ, Doycheva DM, Li B, Zhang Y, Hu Q, He Y, Guo Z, Nowrangi D, Flores J, et al. IRE1alpha inhibition decreased TXNIP/NLRP3 inflammasome activation through miR-17-5p after neonatal hypoxicischemic brain injury in rats. J Neuroinflammation. 2018;15:32.

21. Chen $A, X u Y$, Yuan J. Ginkgolide B ameliorates NLRP3 inflammasome activation after hypoxic-ischemic brain injury in the neonatal male rat. Int J Dev Neurosci. 2018;69:106-11.

22. Chen X, Hovanesian V, Naqvi S, Lim YP, Tucker R, Donahue JE, Stopa EG, Stonestreet BS. Systemic infusions of anti-interleukin-1beta neutralizing antibodies reduce short-term brain injury after cerebral ischemia in the ovine fetus. Brain Behav Immun. 2018;67:24-35.

23. Hazan A, Kumar R, Matzner H, Priel A. The pain receptor TRPV1 displays agonist-dependent activation stoichiometry. Sci Rep. 2015;5:12278.

24. Ramirez-Barrantes R, Cordova C, Poblete H, Munoz P, Marchant I, Wianny F, Olivero P. Perspectives of TRPV1 function on the neurogenesis and neural plasticity. Neural Plast. 2016;2016:1568145

25. Henry RJ, Kerr DM, Flannery LE, Killilea M, Hughes EM, Corcoran L, Finn DP, Roche M. Pharmacological inhibition of FAAH modulates TLR-induced neuroinflammation, but not sickness behaviour: an effect partially mediated by central TRPV1. Brain Behav Immun. 2017;62:318-31.

26. Kong WL, Peng YY, Peng BW. Modulation of neuroinflammation: role and therapeutic potential of TRPV1 in the neuro-immune axis. Brain Behav Immun. 2017;64:354-66.

27. Annunziato L, Boscia F, Pignataro G. Ionic transporter activity in astrocytes, microglia, and oligodendrocytes during brain ischemia. J Cereb Blood Flow Metab. 2013;33:969-82.

28. Giordano C, Cristino L, Luongo L, Siniscalco D, Petrosino S, Piscitelli F, Marabese I, Gatta L, Rossi F, Imperatore R, et al. TRPV1-dependent and -independent alterations in the limbic cortex of neuropathic mice: impact on glial caspases and pain perception. Cereb Cortex. 2012;22:2495-518.

29. Yoshida A, Furube E, Mannari T, Takayama Y, Kittaka H, Tominaga M, Miyata S. TRPV1 is crucial for proinflammatory STAT3 signaling and thermoregulation-associated pathways in the brain during inflammation. Sci Rep. 2016;6:26088.

30. Herrmann JE, Imura T, Song B, Qi J, Ao Y, Nguyen TK, Korsak RA, Takeda K, Akira S, Sofroniew MV. STAT3 is a critical regulator of astrogliosis and scar formation after spinal cord injury. J Neurosci. 2008;28:7231-43.

31. Hristova M, Rocha-Ferreira E, Fontana X, Thei L, Buckle R, Christou M, Hompoonsup S, Gostelow N, Raivich G, Peebles D. Inhibition of signal transducer and activator of transcription 3 (STAT3) reduces neonatal hypoxic-ischaemic brain damage. J Neurochem. 2016;136:981-94.
32. Yin $L$, Dai Q, Jiang P, Zhu L, Dai H, Yao Z, Liu H, Ma X, Qu L, Jiang J. Manganese exposure facilitates microglial JAK2-STAT3 signaling and consequent secretion of TNF-a and IL-1beta to promote neuronal death. Neurotoxicology. 2018;64:195-203.

33. Miyanohara J, Shirakawa H, Sanpei K, Nakagawa T, Kaneko S. A pathophysiological role of TRPV1 in ischemic injury after transient focal cerebral ischemia in mice. Biochem Biophys Res Commun. 2015;467:478-83.

34. Randhawa PK, Jaggi AS. A review on potential involvement of TRPV1 channels in ischemia-reperfusion injury. J Cardiovasc Pharmacol Ther. 2018; 23:38-45.

35. Sofroniew MV, Vinters HV. Astrocytes: biology and pathology. Acta Neuropathol. 2010;119:7-35.

36. Huang WX, Yu F, Sanchez RM, Liu YQ, Min JW, Hu JJ, Bsoul NB, Han S, Yin J, Liu $\mathrm{WH}$, et al. TRPV1 promotes repetitive febrile seizures by pro-inflammatory cytokines in immature brain. Brain Behav Immun. 2015;48:68-77.

37. Vannucci RC, Vannucci SJ. A model of perinatal hypoxic-ischemic brain damage. Ann N Y Acad Sci. 1997;835:234-49.

38. Tian SF, Yang HH, Xiao DP, Huang YJ, He GY, Ma HR, Xia F, Shi XC. Mechanisms of neuroprotection from hypoxia-ischemia $(H I)$ brain injury by up-regulation of cytoglobin (CYGB) in a neonatal rat model. J Biol Chem. 2013:288:15988-6003.

39. Min JW, Hu JJ, He M, Sanchez RM, Huang WX, Liu YQ, Bsoul NB, Han S, Yin J, Liu $\mathrm{WH}$, et al. Vitexin reduces hypoxia-ischemia neonatal brain injury by the inhibition of HIF-1alpha in a rat pup model. Neuropharmacology. 2015;99:38-50.

40. Barca O, Ferre S, Seoane M, Prieto JM, Lema M, Senaris R, Arce VM. Interferon beta promotes survival in primary astrocytes through phosphatidylinositol 3-kinase. J Neuroimmunol. 2003;139:155-9.

41. Luo WD, Min JW, Huang WX, Wang X, Peng YY, Han S, Yin J, Liu WH, He XH, Peng BW. Vitexin reduces epilepsy after hypoxic ischemia in the neonatal brain via inhibition of NKCC1. J Neuroinflammation. 2018;15:186.

42. Zhao SJ, Shen YF, Li Q, He YJ, Zhang YK, Hu LP, Jiang YQ, Xu NW, Wang YJ, Li J, et al. SLIT2/ROBO1 axis contributes to the Warburg effect in osteosarcoma through activation of SRC/ERK/C-MYC/PFKFB2 pathway. Cell Death Dis. 2018;9:390.

43. Neal M, Luo J, Harischandra DS, Gordon R, Sarkar S, Jin H, Anantharam V, Desaubry L, Kanthasamy A, Kanthasamy A. Prokineticin-2 promotes chemotaxis and alternative A2 reactivity of astrocytes. Glia. 2018;66:2137-57.

44. Morrison HW, Filosa JA. A quantitative spatiotemporal analysis of microglia morphology during ischemic stroke and reperfusion. J Neuroinflammation. 2013;10:4.

45. Bouslama M, Renaud J, Olivier P, Fontaine RH, Matrot B, Gressens P, Gallego J. Melatonin prevents learning disorders in brain-lesioned newborn mice. Neuroscience. 2007;150:712-9.

46. Liu XH, Yan H, Xu M, Zhao YL, Li LM, Zhou XH, Wang MX, Ma L. Hyperbaric oxygenation reduces long-term brain injury and ameliorates behavioral function by suppression of apoptosis in a rat model of neonatal hypoxiaischemia. Neurochem Int. 2013:62:922-30.

47. Sanches EF, Arteni NS, Spindler C, Moyses F, Siqueira IR, Perry ML, Netto CA. Effects of pre- and postnatal protein malnutrition in hypoxic-ischemic rats. Brain Res. 2012;1438:85-92.

48. Darre L, Domene C. Binding of capsaicin to the TRPV1 ion channel. Mol Pharm. 2015;12:4454-65.

49. Nikami H, Mahmoud ME, Shimizu Y, Shiina T, Hirayama H, Iwami M, Dosoky RM, Ahmed MM, Takewaki T. Capsaicin pretreatment attenuates LPSinduced hypothermia through TRPV1-independent mechanisms in chicken. Life Sci. 2008:82:1191-5.

50. Touska F, Marsakova L, Teisinger J, Vlachova V. A "cute" desensitization of TRPV1. Curr Pharm Biotechnol. 2011;12:122-9.

51. Samavati L, Rastogi R, Du W, Huttemann M, Fite A, Franchi L. STAT3 tyrosine phosphorylation is critical for interleukin 1 beta and interleukin-6 production in response to lipopolysaccharide and live bacteria. Mol Immunol. 2009:46:1867-77.

52. Freeman L, Guo H, David CN, Brickey WJ, Jha S, Ting JP. NLR members NLRC4 and NLRP3 mediate sterile inflammasome activation in microglia and astrocytes. J Exp Med. 2017;214:1351-70.

53. Yao Y, Chen S, Cao M, Fan X, Yang T, Huang Y, Song X, Li Y, Ye L, Shen N, et al. Antigen-specific CD8(+) T cell feedback activates NLRP3 inflammasome in antigen-presenting cells through perforin. Nat Commun. 2017;8:15402.

54. Spulber $\mathrm{S}$, Bartfai T, Schultzberg M. IL-1/IL-1ra balance in the brain revisited - evidence from transgenic mouse models. Brain Behav Immun. 2009;23:573-9. 
55. Tuttolomondo A, Di Raimondo D, di Sciacca R, Pinto A, Licata G. Inflammatory cytokines in acute ischemic stroke. Curr Pharm Des. 2008;14: 3574-89.

56. Al Mamun A, Yu H, Mirza MA, Romana S, McCullough LD, Liu F. Myeloid cell IRF4 signaling protects neonatal brains from hypoxic ischemic encephalopathy. Neurochem Int. 2018. In Press.

57. ladecola C, Anrather J. The immunology of stroke: from mechanisms to translation. Nat Med. 2011;17:796-808

58. Jellema RK, Lima Passos V, Zwanenburg A, Ophelders DR, De Munter S, Vanderlocht J, Germeraad WT, Kuypers E, Collins JJ, Cleutjens JP, et al. Cerebral inflammation and mobilization of the peripheral immune system following global hypoxia-ischemia in preterm sheep. J Neuroinflammation. 2013;10:13.

59. Pekny M, Pekna M. Astrocyte reactivity and reactive astrogliosis: costs and benefits. Physiol Rev. 2014;94:1077-98.

60. Liao RJ, Jiang L, Wang RR, Zhao HW, Chen Y, Li Y, Wang L, Jie LY, Zhou YD, Zhang $X N$, et al. Histidine provides long-term neuroprotection after cerebral ischemia through promoting astrocyte migration. Sci Rep. 2015:5:15356.

61. Liddelow SA, Barres BA. Regeneration: not everything is scary about a glial scar. Nature. 2016;532:182-3.

62. Rossi DJ, Brady JD, Mohr C. Astrocyte metabolism and signaling during brain ischemia. Nat Neurosci. 2007;10:1377-86

63. Brekke E, Berger HR, Wideroe M, Sonnewald U, Morken TS. Glucose and intermediary metabolism and astrocyte-neuron interactions following neonatal hypoxia-ischemia in rat. Neurochem Res. 2017:42:115-32.

64. Gao S, Mo J, Chen L, Wang Y, Mao X, Shi Y, Zhang X, Yu R, Zhou X. Astrocyte GGTI-mediated Rac1 prenylation upregulates NF-kappaB expression and promotes neuronal apoptosis following hypoxia/ischemia. Neuropharmacology. 2016;103:44-56.

65. Olsen ML, Khakh BS, Skatchkov SN, Zhou M, Lee CJ, Rouach N. New insights on astrocyte ion channels: critical for homeostasis and neuron-glia signaling. J Neurosci. 2015;35:13827-35.

66. Izquierdo $P$, Attwell D, Madry C. Ion channels and receptors as determinants of microglial function. Trends Neurosci. 2019;42:278-92.

67. De Bock M, Decrock E, Wang N, Bol M, Vinken M, Bultynck G, Leybaert L. The dual face of connexin-based astroglial $\mathrm{Ca}(2+)$ communication: a key player in brain physiology and a prime target in pathology. Biochim Biophys Acta. 2014;1843:2211-32

68. Huang WX, Min JW, Liu YQ, He XH, Peng BW. Expression of TRPV1 in the C57BL/6 mice brain hippocampus and cortex during development. Neuroreport. 2014;25:379-85.

69. Martins D, Tavares I, Morgado C. "Hotheaded": the role OF TRPV1 in brain functions. Neuropharmacology. 2014;85:151-7.

70. Ba X, Wang J, Zhou S, Luo X, Peng Y, Yang S, Hao Y, Jin G. Cinobufacini protects against paclitaxel-induced peripheral neuropathic pain and suppresses TRPV1 up-regulation and spinal astrocyte activation in rats. Biomed Pharmacother. 2018;108:76-84.

71. Schilling T, Eder C. Stimulus-dependent requirement of ion channels for microglial NADPH oxidase-mediated production of reactive oxygen species. J Neuroimmunol. 2010;225:190-4

72. Schilling T, Eder C. Importance of the non-selective cation channel TRPV1 for microglial reactive oxygen species generation. J Neuroimmunol. 2009; 216:118-21.

73. Kim SR, Kim SU, Oh U, Jin BK. Transient receptor potential vanilloid subtype 1 mediates microglial cell death in vivo and in vitro via Ca2 + -mediated mitochondrial damage and cytochrome c release. J Immunol. 2006;177:4322-9.

74. Lopez-Requena A, Boonen B, Van Gerven L, Hellings PW, Alpizar YA, Talavera K: Roles of neuronal TRP channels in neuroimmune interactions. In Neurobiology of TRP Channels. Edited by nd, Emir TLR. 2nd edition. Frontiers in Neuroscience. Boca Raton; 2017. p. 277-294.

75. Miyake T, Shirakawa H, Nakagawa T, Kaneko S. Activation of mitochondrial transient receptor potential vanilloid 1 channel contributes to microglial migration. Glia. 2015;63:1870-82.

76. Ho KW, Lambert WS, Calkins DJ. Activation of the TRPV1 cation channel contributes to stress-induced astrocyte migration. Glia. 2014;62:1435-51.

77. Jha MK, Jo M, Kim JH, Suk K. Microglia-astrocyte crosstalk: an intimate molecular conversation. Neuroscientist. 2018:1073858418783959. https://doi. org/10.1177/1073858418783959.

78. Zhang E, Liao P. Brain transient receptor potential channels and stroke. J Neurosci Res. 2015:93:1165-83.
79. Zamanian JL, Xu L, Foo LC, Nouri N, Zhou L, Giffard RG, Barres BA. Genomic analysis of reactive astrogliosis. J Neurosci. 2012:32:6391-410.

80. Song C, Zhang Y, Dong Y. Acute and subacute IL-1 beta administrations differentially modulate neuroimmune and neurotrophic systems: possible implications for neuroprotection and neurodegeneration. J Neuroinflammation. 2013;10:59.

81. Gabrysova L, Howes A, Saraiva M, O'Garra A. The regulation of IL-10 expression. Curr Top Microbiol Immunol. 2014;380:157-90.

82. Li CH, Xu LL, Jian LL, Yu RH, Zhao JX, Sun L, Du GH, Liu XY. Stattic inhibits RANKL-mediated osteoclastogenesis by suppressing activation of STAT3 and NF-kappaB pathways. Int Immunopharmacol. 2018:58:136-44.

83. Liu J, Feng ZC. Increased umbilical cord plasma interleukin-1 beta levels was correlated with adverse outcomes of neonatal hypoxic-ischemic encephalopathy. J Trop Pediatr. 2010;56:178-82.

84. Kim HJ, Lee DW, Ravichandran K, D OK, Akcay A, Nguyen Q, He Z, Jani A, Ljubanovic D, Edelstein CL. NLRP3 inflammasome knockout mice are protected against ischemic but not cisplatin-induced acute kidney injury. J Pharmacol Exp Ther. 2013;346:465-72.

85. Heneka MT, Kummer MP, Stutz A, Delekate A, Schwartz S, Vieira-Saecker A Griep A, Axt D, Remus A, Tzeng TC, et al. NLRP3 is activated in Alzheimer's disease and contributes to pathology in APP/PS1 mice. Nature. 2013;493: 674-8.

86. Kose SA, Naziroglu M. Selenium reduces oxidative stress and calcium entry through TRPV1 channels in the neutrophils of patients with polycystic ovary syndrome. Biol Trace Elem Res. 2014;158:136-42.

\section{Ready to submit your research? Choose BMC and benefit from:}

- fast, convenient online submission

- thorough peer review by experienced researchers in your field

- rapid publication on acceptance

- support for research data, including large and complex data types

- gold Open Access which fosters wider collaboration and increased citations

- maximum visibility for your research: over $100 \mathrm{M}$ website views per year

At $\mathrm{BMC}$, research is always in progress.

Learn more biomedcentral.com/submissions 